\title{
Temporal dynamics of face selection mechanism in the context of similar and dissimilar faces: ERP evidence for biased competition within the ventral occipito-temporal cortex using ICA
}

Citation for published version (APA):

Gentile, F., \& Jansma, B. M. (2012). Temporal dynamics of face selection mechanism in the context of similar and dissimilar faces: ERP evidence for biased competition within the ventral occipito-temporal cortex using ICA. Neuroimage, 59(1), 682-694. https://doi.org/10.1016/j.neuroimage.2011.07.018

Document status and date:

Published: 01/01/2012

DOI:

10.1016/j.neuroimage.2011.07.018

Document Version:

Publisher's PDF, also known as Version of record

Document license:

Taverne

Please check the document version of this publication:

- A submitted manuscript is the version of the article upon submission and before peer-review. There can be important differences between the submitted version and the official published version of record. People interested in the research are advised to contact the author for the final version of the publication, or visit the $\mathrm{DOI}$ to the publisher's website.

- The final author version and the galley proof are versions of the publication after peer review.

- The final published version features the final layout of the paper including the volume, issue and page numbers.

Link to publication

\footnotetext{
General rights rights.

- You may freely distribute the URL identifying the publication in the public portal. please follow below link for the End User Agreement:

www.umlib.nl/taverne-license

Take down policy

If you believe that this document breaches copyright please contact us at:

repository@maastrichtuniversity.nl

providing details and we will investigate your claim.
}

Copyright and moral rights for the publications made accessible in the public portal are retained by the authors and/or other copyright owners and it is a condition of accessing publications that users recognise and abide by the legal requirements associated with these

- Users may download and print one copy of any publication from the public portal for the purpose of private study or research.

- You may not further distribute the material or use it for any profit-making activity or commercial gain

If the publication is distributed under the terms of Article $25 \mathrm{fa}$ of the Dutch Copyright Act, indicated by the "Taverne" license above,

Download date: 26 Apr. 2023 


\title{
Temporal dynamics of face selection mechanism in the context of similar and dissimilar faces: ERP evidence for biased competition within the ventral occipito-temporal cortex using ICA
}

\author{
F. Gentile* , B.M. Jansma \\ Department of Cognitive Neuroscience, Faculty of Psychology and Neuroscience, Maastricht University, The Netherlands \\ Maastricht Brain Imaging Center (M-BIC), Maastricht University, The Netherlands
}

\section{A R T I C L E I N F O}

\section{Article history:}

Received 21 December 2010

Revised 21 June 2011

Accepted 7 July 2011

Available online 19 July 2011

\section{Keywords:}

Biased Competition

Face selection

Visual similarity

N170

N250

ICA

\begin{abstract}
A B S T R A C T
This study was designed to investigate the spatio-temporal characteristic of face selection in the context of the Biased Competition (BC) model using electroencephalography (EEG). Pairs of similar (SIM) or dissimilar (DISS) faces were presented simultaneously. Subjects had to attend to one face (ATT) or ignore both faces (IGN). According to the BC account, simultaneously presented faces compete for representation. Spatial attention biases these competitive interactions towards neural processing of the attended face alone. A preceding functional magnetic resonance imaging (fMRI) study confirmed the validity of BC as selection principle in the occipital face area (OFA) and in the fusiform face area (FFA) (IGN SIM $<$ IGN DISS; ATT $\mathrm{SIM}=$ ATT DISS) (Gentile and Jansma, 2010). The directionality of the similarity modulation within the IGN condition was interpreted in line with the assumption that within FFA similar faces are more likely to be encoded by largely overlapping population of neurons, hence leading to a stronger competition. In the present EEG experiment we investigated when neural competition and the bias effect take place. Using independent component analysis (ICA), we focused on face-processing-related components N170 and N250. Whereas we could not find any context-dependent modulation of the N170, we observed a context $\mathrm{x}$ task interaction within the N250 time-window. Together, the fMRI and EEG results suggested that faces competed for representation (IGN SIM $<$ IGN DISS) in the N250 time-window within FFA. In addition, at the same latency (250 ms post-stimulus onset) and region of interest (FFA) the data supported the idea that attention solved neural competition in favor of the relevant face (ATT SIM = ATT DISS). We also observed a main effect of attention frontally within the N2b time-window, i.e. about 50 ms later than the attentional bias that solved competitive interactions. Based on these findings, it is plausible to conclude that this frontal activity was not directly involved in the bias control during selection in FFA.
\end{abstract}

(C) 2011 Elsevier Inc. All rights reserved.

\section{Introduction}

Due to its limited capacity, the visual system is not able to fully process several stimuli at the same time. Attentional mechanisms are needed to select the task-relevant item in a clutter of other objects (Broadbent, 1958; Carrasco et al., 2004; Desimone and Duncan, 1995; Hawkins et al., 1990; Luck et al., 1994; Treisman, 1969). According to the classical view, attention works as a "spotlight" that enhances the neural representation of the attended stimulus (Brefczynski and DeYoe, 1999; Hillyard and Munte, 1984; Luck et al., 1994; Posner et al., 1980; Reynolds et al., 2000). The influence of attention on visual processing was further elaborated by models of attention that assumed a competitive interaction among items simultaneously

\footnotetext{
* Corresponding author at: Department of Cognitive Neuroscience, Faculty of Psychology and Neuroscience, Maastricht University, P. O. Box 616, 6200 MD Maastricht, The Netherlands. Fax: + 31433884125.

E-mail address: f.gentile@maastrichtuniversity.nl (F. Gentile).
}

presented and ignored. The most influential one is the Biased Competition (BC) model. According to $\mathrm{BC}$, when two stimuli are presented at the same time within the receptive field of a neuron, the neural representations of the two items interact in a mutually suppressive manner. In this framework, attention acts to bias the neural competition between the two competing items in favor of the neural processing of the attended one (Desimone, 1998; Desimone and Duncan, 1995; Kastner and Ungerleider, 2000, 2001; Pessoa et al., 2003; Reynolds and Desimone, 1999).

Several electrophysiological studies tested this model in monkeys. The classical design consisted of presenting simultaneously two different items within the receptive field of the recorded cells in the visual cortex, while the monkey ignored the stimuli. In such an experimental setting the cells' firing rate related to the objects was a weighted average of the activity of the same items presented alone. In line with the $\mathrm{BC}$ model, these results suggested that multiple objects compete for representation. In the context of neural competition, the effect of attention was also investigated. The neural activity associated 
with attending to one item in a group of other objects was comparable to the activity related to the processing of the same items presented alone and being ignored (Recanzone, 2000; Reynolds et al., 1999). These results confirmed the role of attention as the bias control needed to select the stimulus relevant for behavior (Chelazzi et al., 1998, 2001; Desimone and Duncan, 1995; Luck et al., 1997; Miller et al., 1993; Moran and Desimone, 1985; Reynolds et al., 1999; Treue and Martinez Trujillo, 1999; Treue and Maunsell, 1996). According to Reynolds and Desimone (1999), the competing interactions between stimuli representations are caused by the inhibitory connections projecting from the cells encoding the stimuli to the recorded neuron. In addition, attention to one of the stimuli suppresses the inhibiting influence of the unattended stimulus. This in turn makes the attended stimulus the only one that is processed as relevant.

The $\mathrm{BC}$ model was also tested in the human visual cortex with functional magnetic resonance imaging (fMRI). A first series of experiments focused on the competitive aspect of BC. They showed that when several items were simultaneously presented the fMRI signal decreases compared to when they were presented one at a time. This result was interpreted as a suppression effect due to neural competition among the items in the cluster (Beck and Kastner, 2005, 2007; Kastner et al., 1998, 1999, 2001). The attentional bias hypothesis of the BC model was approached by another series of studies. They observed a general enhancement of activation when both top-down and bottom-up attentional mechanisms came into play. In particular, the fMRI signal increased up to the level of the activation elicited by the same objects presented alone whenever one stimulus in a cluster of other stimuli was attended to (Beck and Kastner, 2005; Bles et al., 2006; Kastner et al., 1999).

A recent fMRI experiment by Reddy et al. (2009) tested the BC model by presenting complex stimuli (e.g. faces, objects and buildings) either in isolation or as pairs. A weighted average and a weighted sum model were tested by comparing the condition where subjects attended to both items vs. when they attended only to one of them. The results supported the weighted average model suggesting that the two presented stimuli compete for representation. The study also demonstrated that the amount of competition in FFA was limited in case a face was paired with a stimulus belonging to a different category (e.g. building and objects), indicating differences in the inhibitory influence within and between categories.

Jacques and Rossion $(2004,2007)$ investigated context effects in face selection using electroencephalography (EEG). The authors observed that the face-related N170 component decreased in amplitude when a laterally presented target face appeared next to a centrally fixated face, as compared to when a scrambled face was present in the center. These results were replicated with a central target face appearing in between two lateral faces vs. two scrambled faces (Jacques and Rossion, 2006). In line with the study by Reddy et al. (2009), this result indicates that the extent of neural competition is larger when a face is paired with another face rather than with a nonface stimulus.

In an fMRI study we further investigated this idea by focusing on the interaction between two faces when they were simultaneously presented (Gentile and Jansma, 2010). In particular we tested whether the amount of competition is related to the characteristics of the neural population codes. This hypothesis was inspired by the studies of Jiang et al. (2006) and Loffler et al. (2005) which suggested that similar faces are more likely to be encoded by largely overlapping population of neurons than dissimilar faces (Fujita et al., 1992; Kreiman et al., 2006; Sato et al., 2009; Tamura et al., 2005; Tanaka, 2003; Wang et al., 1998; Young and Yamane, 1992). Therefore, presenting a pair of similar faces would result in a higher competition effect due to the stronger inhibitory connections within overlapping population of neurons. This would lead to a lower fMRI signal within FFA compared to processing dissimilar faces. This working hypothesis was confirmed by our results as we observed a significant decrease in
fMRI signal for the ignore-similar-faces condition vs. the ignoredissimilar-faces condition in FFA and in another face-sensitive area in the inferior occipital cortex, the occipital face area (OFA) (Gentile and Jansma, 2010). This similarity modulation within the ignore-faces condition suggested that faces were both encoded and competed for representation both in OFA and in FFA. In order to investigate the effect of attention on the competitive interactions between faces, we included an attend-to-face condition where the participants had to attend to one of the faces and perform a match to sample task. We observed that during the attend-to-face condition activation in OFA and FFA was indistinguishable for similar and dissimilar faces displays, confirming that attention is needed to bias neural competition in favor of the processing of the target. Overall, these results suggested that face selection takes place via biased competition.

However, due to the sluggishness of the hemodynamic response, it was not possible to track the dynamics of such a mechanism. In the present study we used EEG to investigate when the two main components of BC, "competition" and "bias", take place. The stimuli display, the experimental design and the procedure were identical for the EEG and the fMRI study (Gentile and Jansma, 2010).

In the classical $\mathrm{BC}$ paradigm, neural competition between the neural representations of two stimuli in early visual areas was tested by presenting those items alone (sequential condition) and comparing the resulting activation with the same items presented simultaneously (simultaneous condition). In the present experiment and in the previously reported fMRI study, we purposely did not include sequences of single faces mainly for two reasons. First, such a condition is characterized by a higher amount of transients compared to pairs of faces presented simultaneously. This could give rise to an overestimation of neural competition occurring in the latter condition. Secondly, neural adaptation could take place for a sequence of similar faces presented alone (Jiang et al., 2006; Loffler et al., 2005) and in turn cause an underestimation of the neural competition in the similar case when comparing sequential vs. simultaneous condition. In order to avoid both these confounds we introduced the attend-toface condition that had the same amount of transients as the ignorefaces condition and it was not influenced by neural adaptation and hence offers an alternative way to study BC. In addition, as already mentioned above, Recanzone (2000) and Reynolds et al. (1999) showed that when attention was directed to one of the items presented in a multiple display, the neural response increased up to the level of the response to the single item presented alone. A recent fMRI study confirmed this idea in the face perception domain as it showed that the attend-to-face condition is a suitable baseline for single-face processing (Reddy et al., 2009).

The EEG signal was recorded from 32 electrodes and analyzed via the Independent Component Analysis (ICA) (Debener et al., 2005a; Onton and Makeig, 2006). ERP studies suggest that the visual processing of a face occurs through at least two stages: an early and a later stage. The former was first identified by a significant difference for a negative potential around $170 \mathrm{~ms}$ after stimulus onset when faces were compared with non-face stimuli. This component known as the N170 is most prominent at occipito-temporal electrodes (Bentin et al., 1996; Botzel et al., 1995; Jeffreys, 1989; Rossion and Jacques, 2008). The N170 has been associated with the perceptual encoding stage of faces (Bentin et al., 1996) and it has been shown to be sensitive to the difference between individual faces (Jacques and Rossion, 2007, 2009). Results from different types of source localization procedures indicate that the N170 might originate either in the lateral occipitotemporal cortex (likely corresponding to OFA) (Botzel et al., 1995; Deffke et al., 2007; Pizzagalli et al., 2002; Rossion et al., 2003b; Schweinberger et al., 2002; Shibata et al., 2002) or in the middle/anterior fusiform gyrus (normally associated with FFA) (Henson et al., 2007; Herrmann et al., 2005; Mnatsakanian and Tarkka, 2004). A second component, the occipito-temporal N250, shows a larger response to faces than other stimuli and is even more 
sensitive to face identity compared to the N170, in particular for familiar faces (Schweinberger et al., 2002, 2004). With regard to neural sources, the face related $\mathrm{N} 250$ has been consistently localized within FFA (Schweinberger et al., 2002, 2004, 2007).

Based on the results of the preceding fMRI study (Gentile and Jansma, 2010), we expected that the two faces were automatically encoded and competed for representation when they were ignored. Therefore, we expected to find a similarity modulation in the ignorefaces condition (IGN_SIM $<$ IGN_DISS) either at the level of the N170 or in correspondence of the N250.

In the fMRI experiment, the similarity factor modulated OFA and FFA only within the ignore-faces condition. However, in the attend-toface task the fMRI signal was comparable for similar and dissimilar faces (ATT_SIM = ATT_DISS). This lack of similarity modulation suggested that attending to one of the two faces solved (or biased) neural competition towards the processing of that face only. In line with this result we expected to observe the same bias effect at that stage of face processing sensitive to the mutual interaction between the two faces or eventually at a later stage.

In our previous study, OFA and FFA (as measured in fMRI) also showed a main effect of attention (ATT $>$ IGN). A large network of prefrontal regions was detected as a potential source of this attentional modulation and in turn of the bias signal that solved neural competition between the two faces. In the present study the high temporal resolution of EEG was used to verify this hypothesis. We investigated whether the two mechanisms (attention and bias) have a common origin or whether they are functionally distinct in time and location. Differences in temporal processing of various neural events were identified via latency shifts between occipitally and frontally distributed ERP components. In particular, under the assumption that frontal areas drive the BC process in OFA and FFA, we expected to find an early frontal ERP modulation related to covert attention and selection and a relatively late BC modulation of a facerelated ERP component.

\section{Methods}

\section{Subjects}

Nineteen healthy volunteers (17 females, two left-handed) with normal or corrected to normal visual acuity participated in this study. The age of participants ranged from 18 to 28 years. They were all students recruited at Maastricht University and their participation was compensated with academic credit points. After explanation of the procedures, participants signed an informed consent form. The study was approved by the ethical committee of the faculty. One of the subjects was discarded from the analysis due to technical difficulties during the EEG measurement.

\section{Stimuli}

The stimuli were identical to the preceding fMRI study (Gentile and Jansma, 2010). In particular, the stimuli consisted of two sets of 16 pairs of faces. One set represented similar (SIM) and the other dissimilar (DISS) faces (see Figs. 1 and 2.b for examples). The faces in the pairs were selected from a large set of pictures of faces (total of 60 pictures) provided by Mark Steyvers (http://psiexp.ss.uci.edu/ research/software.htm). The pictures were all taken under similar lightning with neutral facial expressions (Kayser, 1985).

Similarity between faces was defined by using the two major approaches adopted for face representation: the purely psychological or top-down approach and the purely computational or bottom-up approach (see Figs. 1.a,b). Both approaches are based on the multidimensional representation of faces (Steyvers and Busey, 2000) and are described in details elsewhere (Gentile and Jansma, 2010).
The final set of stimuli was derived as follows: a pair of faces was labeled as a SIM (or DISS) pair, only if both faces were labeled as such in the top-down as well as in the bottom-up approach (see Fig. 1.c). We then computed the distance of both sets of faces from a mean face in order to avoid differences in the level of activation within FFA, across conditions (Loffler et al., 2005). SIM and DISS faces were, on average, at the same distance from the mean face.

The stimulus display we presented to the participants consisted of two SIM or DISS faces positioned in opposite hemifield. The single pictures subtended approximately $4.1^{\circ}$ (height) $\times 3.5^{\circ}$ (width) of visual angle and were aligned to the center of the screen. The entire visual display covered $4.1^{\circ}$ (height) $\times 7.8^{\circ}$ (width) of visual angle. The display size was designed to be comparable with those used in previous studies on face processing (Gauthier et al., 2000; Halgren et al., 1999; Kanwisher et al., 1997; Rossion et al., 2003a; Steeves et al., 2006; Wojciulik et al., 1998). Therefore, it was reasonable to assume that FFA integrated the two simultaneously presented faces within each experimental trial (Halgren et al., 1999; Reinholz and Pollmann, 2007). The stimuli (SIM and DISS) were identical for both the IGN and ATT tasks and they were delivered using the Presentation 12.2 package (Neurobehavioral Systems, Inc. www.neurobs.com).

\section{Procedure and design}

The procedure as well as the stimuli was identical to the fMRI study (Gentile and Jansma, 2010). After the explanation of the two tasks (IGN, ATT), and the application of the electrodes, participants were comfortably seated in an electrically shielded, sound-attenuated room in front of a computer monitor at a distance of $80 \mathrm{~cm}$.

The main experiment consisted of four runs in a block-design (Fig. 2.a). Each run consisted of 4 blocks and started with a blank screen with a white fixation cross lasting for $3 \mathrm{~s}$. At the beginning of each block a visual instruction (ATT and IGN condition, see below) was presented for $3 \mathrm{~s}$, followed by a white cross on a blank screen after which the trial started. A block consisted of thirty-nine trials. A single trial started with the presentation of a white fixation cross in the center of a blank screen of varying duration (mean $2500 \mathrm{~ms}$, range 2000-3000 ms), followed by the two faces presented for $500 \mathrm{~ms}$. When the stimuli were presented, the fixation cross changed into two bars $\left(0.2^{\circ}\right.$ in height $)$ that were placed between the two faces $\left(0.17^{\circ}\right.$ above and below the center of the screen). A block of trials ended with a resting condition consisting of a blank screen with a white cross lasting for $2 \mathrm{~s}$.

The visual instruction for the IGN task consisted of two keywords ('streep-breedte', 'line-width' in English) centered on the screen They instructed the subject to perform a bar-width discrimination task in the center of the display, while ignoring the background (Figs. 2.a,b). More specifically, participants had to attend to the two bars in the center and a button-press was required when the bars matched in width. The width of the bars varied between 1 and 5 pixels. For the ATT task, the instruction consisted of a picture of a face, on which the subject had to perform a match-to-sample task. For each trial, participants were asked to respond via a button press when the face presented on the left side of the screen matched the one presented in the instruction phase (Figs. 2.a,b). For this task, subjects were instructed beforehand to avoid saccades and to covertly attend to the item on the left while fixating the center. In both IGN and ATT conditions, targets occurred on average $20 \%$ of the time. In analogy to preceding biased competition studies (Bles et al., 2006) targets always occurred at the target position, on the left side of the visual field. The subject was asked to respond as fast and accurately as possible within a $1500 \mathrm{~ms}$ time-window (comprising the face pair display duration and 1 second of blank screen) by using the index finger.

The design was a $2 \times 2$ repeated measures design with factors task (ATT, IGN) and similarity (SIM, DISS), leading to 4 conditions (IGN_SIM, IGN_DISS, ATT_SIM, ATT_DISS, see Fig. 2.c). The participants were not 
a

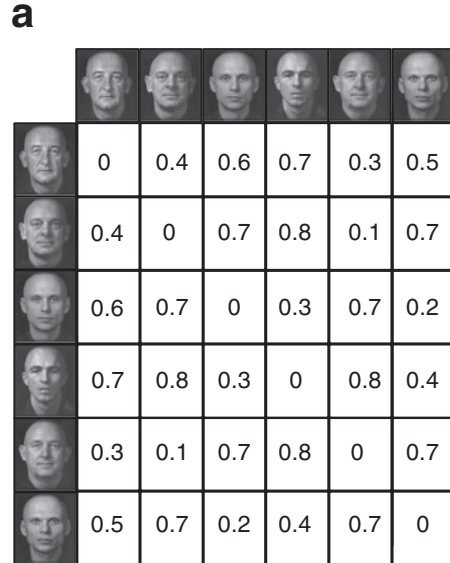

b

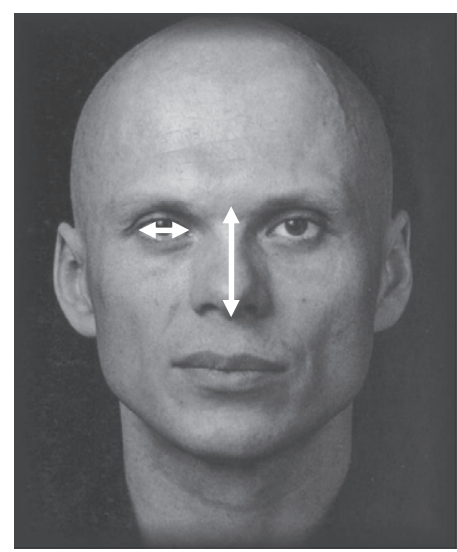

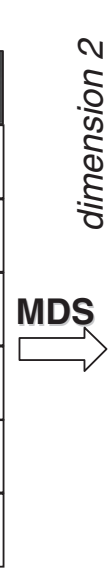
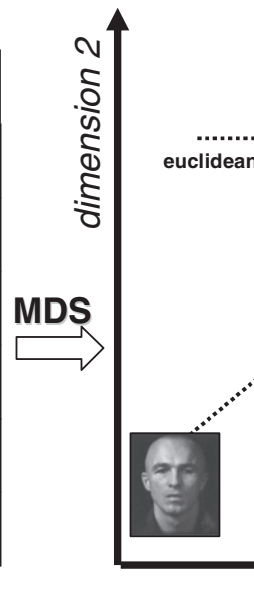

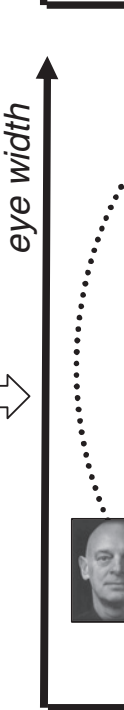

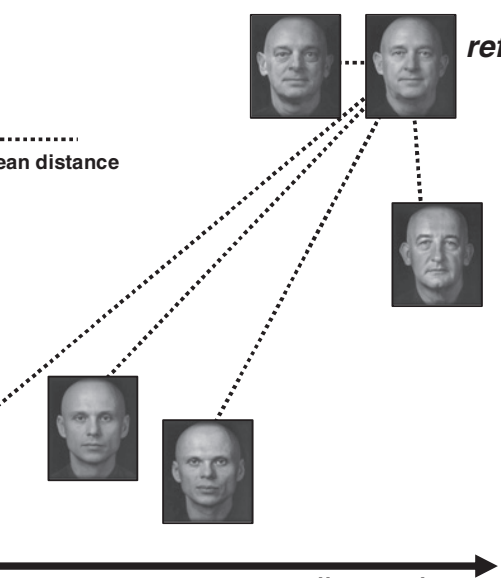

reference face

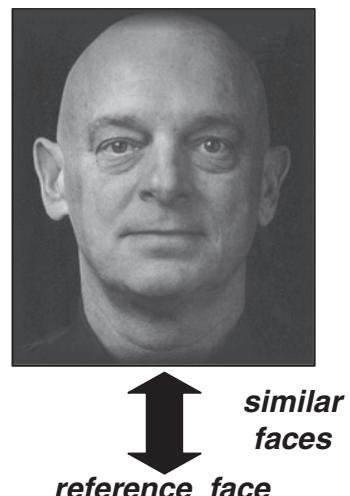

C
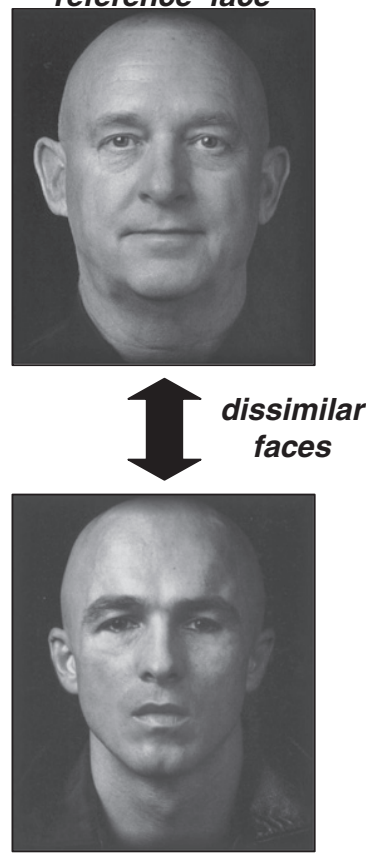

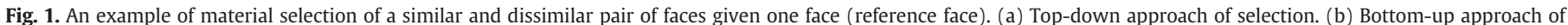
selection. (c) Result of selection: combination of results from both approaches.

made aware of the similarity manipulation between the two faces. The order of the blocks was randomized and counterbalanced across participants and runs by means of the Williams design (Williams, 1949). This scheme is a generalized Latin square design, balanced for first-order carryover effects. Participants were instructed to fixate the center of the screen throughout the experiment and to minimize head and eye-movements for the whole duration of the experiment. The entire session lasted approximately $60 \mathrm{~min}$.

\section{EEG recording}

The electroencephalogram (EEG) was measured using 29 tin electrodes mounted in an elastic cap (QuickCap, Neuroscan Inc. Tm). The electrodes were positioned according to the international 10-20 system (Klem et al., 1999) with the electrodes Fz, F3, F4, F7, F8, FCz, FC3, FC4, FP1, FP2, AFz, T3, T4, T5, T6, TP7, TP8, Cz, C3, C4, CPz, CP3, CP4, Pz, P3, P4, Oz, O1, O2 (Fig. 3). Reference electrodes were positioned at both mastoids (A1, A2). The left mastoid (A1) was used as online reference for the electrical signal measured on the scalp. Vertical eye movements and eye-blinks were monitored by a bipolar montage placed above and below the left upper and lower orbital ridge. Horizontal eye movements were recorded with a bipolar montage placed at the left and right canthi. Electrode impedance was kept below $5 \mathrm{~K} \Omega$. EEG data were recorded and amplified using
Neuroscan SynAmps with a $0.05-30 \mathrm{~Hz}$ bandpass and sampled at 4ms intervals $(250 \mathrm{~Hz})$.

Analysis

EEG data were epoched with an interval of $900 \mathrm{~ms}$, time-locked to the onset of the presentation of the pair of faces. Epochs included a 100 -ms pre-stimulus baseline correction interval and they were $0.3-$ $30 \mathrm{~Hz}$ bandpass filtered (Butterworth, zero phase, $24 \mathrm{~dB} / \mathrm{oct}$ ).

Data were decomposed in independent components (ICs) via ICA (Onton and Makeig, 2006). The ICA algorithm takes as input the EEG signal recorded at the scalp channels and considers each of these signals as a linear mixture of temporal independent components. ICA searches for those time courses in the mixture that are maximally independent to each other. The ICs represent the brain sources that give rise to the signal recorded over the scalp. This assumption arises from the observation that the density of local synaptic contacts among pyramidal cells is much larger than the long-range connections. Therefore, it is plausible to consider, across a reasonable amount of time, the brain as divided into separate functional areas. These areas are supposed to contribute to temporally independent neural processes within a time-window of interest. The ICA model also assumes that these activities originating in the cortex are spatially constant and project onto the scalp instantaneously and linearly via 


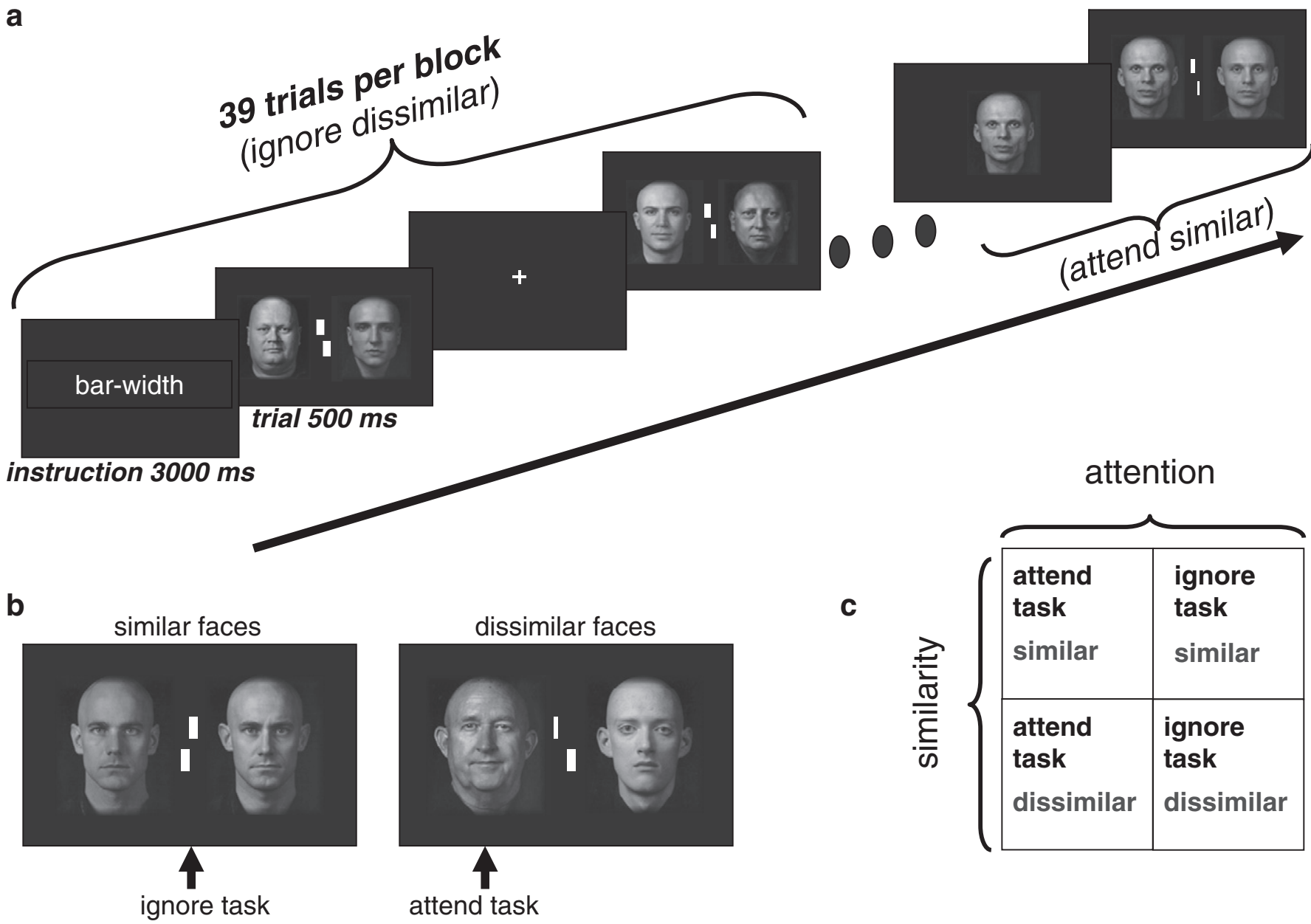

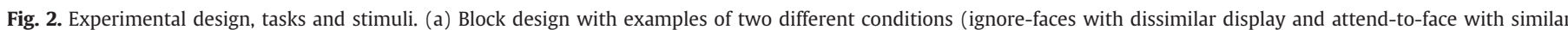

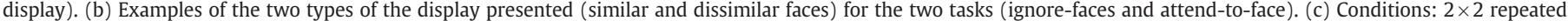
measures design.

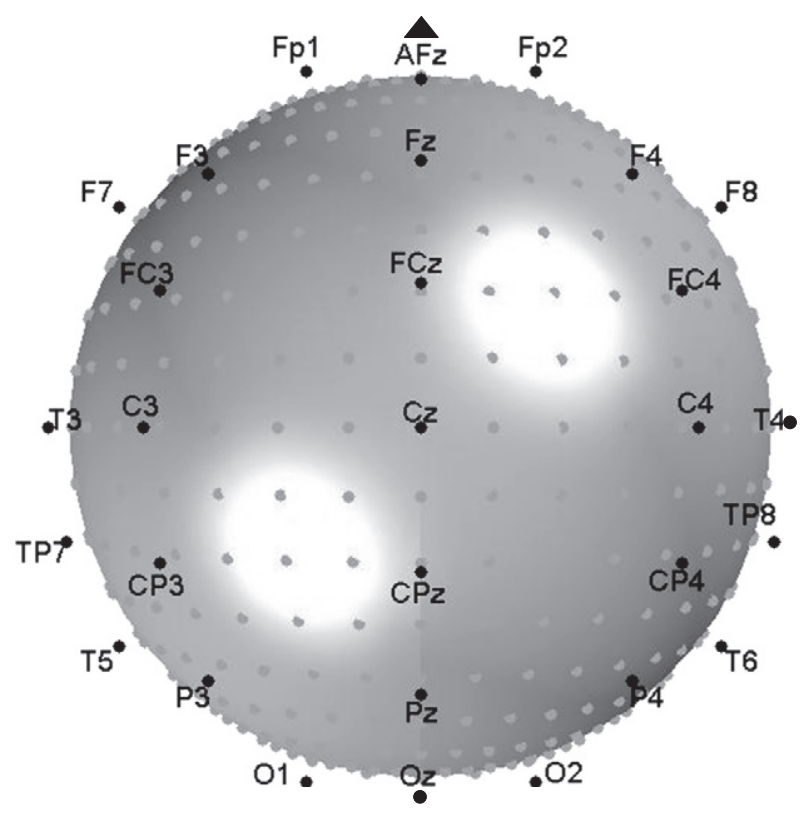

Fig. 3. Layout of the electrodes-position. volume conduction. As brain sources are not the only sources contributing to the signal on the scalp, different type of artifacts (e.g. eye-blinks, muscle and heart beat artifact) are also included in the model. In summary, the signal at each electrode can be considered as a linear mixture of independent cortical and non-cortical sources that is spatially fixed over time and that are identified by ICA. This type of analysis is relevant especially when several neural mechanisms work in parallel or in overlapping time-windows (e.g. perception, neural competition and attention - as in the present case).

Before running the ICA we removed those artifacts that were particularly problematic for the ICA algorithm. They mainly consisted of large muscle movements that give rise to high amplitude and high frequency noise. In addition, large muscle movements and other irregular artifacts are unique, non-stereotyped and most importantly associated with one single component each. Visual inspection was used to remove the epochs characterized by this type of artifacts.

After the pruning procedure, the concatenated single-trial data sets were decomposed using infomax ICA implemented in EEGLAB (http://sccn.ucsd.edu/eeglab). The ICA decomposition gave rise to 32 temporal ICs (complete decomposition) and for each component 32 weights were extracted. These weights represented the relative contribution of a specific component to the 32 electrode signal. Therefore, a single IC was characterized by a time course and a scalp map made of the weights associated to that component and representing the projection on the scalp of its neural generator. 
We also performed dipole source modeling on the scalp maps associated with the ICs-time-courses (Debener et al., 2005b; Onton and Makeig, 2006). In particular, the DIPFIT algorithm of EEGLAB searched for the one or two equivalent current dipole models whose projection best-fitted the spatial distribution of a given IC-map. Compared to the standard approach, the advantage of solving the inverse problem on the IC-maps is that each IC is thought to represent the activity of a single cortical source which generates a specific spatial pattern on the scalp (IC-map). The components fitting the model with a residual variance lower than $15 \%$ were kept for further analysis.

The ICs that verified the latter constraint were collected from all subjects and were, in turn, divided into clusters according to their scalp distribution and temporal dynamics. We first defined a few groups of components characterized by the same spatial distribution of their scalp maps. Similarly, we defined groups of ICs identified by an ERP time course that was represented by a prominent negativity or positivity in a specific time-window. The ICs that had the same ERP morphology and spatial distribution (scalp maps) were clustered across subjects.

From the IC time course were extracted the ERPs related to the 4 conditions (IGN_SIM, IGN_DISS, ATT_SIM, ATT_DISS) excluding target trials. The scalp topography and the event-related average of the IC time course were used to separate task-related and artifacts components. We isolated stereotyped artifact, repeating over time, like eye-movement, eye-blink and some restricted category of muscle movement (e.g. heart beat and muscle tension). The remaining brain-activity related components were collected from all subjects.

Statistics on the components in a cluster were performed on the associated ERPs. In particular, we computed for each ERP the peak latency of the negativity (or positivity) characterizing that cluster. The mean amplitude was calculated for a time-window $+/-30 \mathrm{~ms}$ around the peak for all conditions, subjects, and components. In order to have one single statistical entry per subject, the corresponding amplitude values were averaged together if several ICs were associated to the same subjects. These values were submitted to a repeated measures ANOVA. The same statistical analysis as for the ICERPs was performed by considering the minimum (maximum) envelope of their back-projections on the scalp. The back-projections of the ICs were then used to evaluate the contribution of each cluster to the variance related to the grand ERP average in a specific timewindow.

\section{Results}

\section{Behavioral results}

We computed error rates (ERs) and reaction times (RTs) on the IGN and ATT task for SIM and DISS conditions. Mean error rates and RTs were then submitted to a repeated measures ANOVA with two factors attention and similarity. No significant main effects of attention ( $F(1$, $17)=0.01, p=.934$, mean RT ATT $=738 \mathrm{~ms}, \mathrm{SE}=29$, IGN $=737 \mathrm{~ms}$, $\mathrm{SE}=36)$, similarity $(\mathrm{F}(1,17)=1.08, \mathrm{p}=.313$, mean $\mathrm{RT} \mathrm{SIM}=730 \mathrm{~ms}$, $\mathrm{SE}=28$, DISS $=746 \mathrm{~ms}, \mathrm{SE}=36)$ or interaction $(\mathrm{F}(1,17)=0.25$, $\mathrm{p}=.620$ ) were observed for RTs. The same analysis on ERs did not reveal any main effect of attention $(F(1,17)=0.00, p=.953$, mean ER $\mathrm{ATT}=28 \%, \mathrm{SE}=5, \mathrm{IGN}=28 \%, \mathrm{SE}=3)$ or similarity $(\mathrm{F}(1,17)=1.65$, $\mathrm{p}=.216$, mean $\mathrm{ER} \mathrm{SIM}=26 \%, \mathrm{SE}=2$, DISS $=30 \%, \mathrm{SE}=5)$. Unlike the RTs results, the interaction of factors attention and similarity was significant for the ERs $(F(1,17)=6.75, p=.019)$. The pairwise comparisons showed that the difference between dissimilar and similar condition within the attend-to-faces condition approached significance (ATT_SIM $<$ ATT_DISS: $\mathrm{F}=3.59, \mathrm{p}=.075$; IGN_SIM $>$ IGN_SIM: $\mathrm{F}=2.23$, $\mathrm{p}=0.153)$.

\section{ICA clusters and estimated sources}

The ICA cluster analysis revealed 3 clusters of interest namely the N170, N250 and N2b-cluster. The N170-cluster consisted of 11 components from 11 subjects. They were characterized by a negativity peaking around $180 \mathrm{~ms}$. A $2 \times 2$ ANOVA performed on the ICs did not reveal any main effect of attention, similarity or interaction of factors for this cluster (Fig. 4.a).

The IC scalp maps showed a central occipital distribution. These maps were used for source dipole modeling. In particular, as in ICA a central component is likely to be generated by two synchronized sources, we modeled the neural generators of the N170 with two bilateral cortical sources. The occipital distribution of the N170-ICs topography suggested that those sources were located in a region more posterior than FFA. In line with a more occipital origin of the N170, some studies suggested that this component is generated within a face selective region located on the lateral bank of the lateral occipital complex (LOC) and defined as OFA (Botzel et al., 1995; Deffke et al., 2007; Pizzagalli et al., 2002; Rossion et al., 2003b; Schweinberger et al., 2002; Shibata et al., 2002). Therefore, in order to investigate whether OFA was a realistic source of the N170, we seeded a two-equivalent current dipole into the centro-lateral part of the inferior occipital gyrus (Fig. 4.b). This source dipole model accounted on average for $98.41 \%$ of the observed variance (97.29\%-99.15\%).

The clustering procedure revealed another face-specific cluster defined as the N250-cluster whose components (17 ICs extracted from 12 subjects) were identified by a negative deflection around $230 \mathrm{~ms}$. The statistical analysis on these components revealed a significant interaction of factors attention and similarity (Fig. 5.a). Attention: $(\mathrm{F}(1,11)=.017, \mathrm{p}=.898$, mean amplitude ATT $=-1.4$, $\mathrm{SE}=.423, \mathrm{IGN}=-1.4, \mathrm{SE}=.395)$. Similarity: $(\mathrm{F}(1,11)=1.896$, $\mathrm{p}=.196$, mean amplitude $\mathrm{SIM}=-1.4, \mathrm{SE}=.409, \mathrm{DISS}=-1.46$, $\mathrm{SE}=.399)$. Interaction: $(\mathrm{F}(1,11)=5.316, \mathrm{p}=.042)$. The interaction effect was further investigated by comparing the similar vs. dissimilar condition within the attend-to-face and the ignore-faces condition separately. The pairwise comparisons showed no difference in the attend-to-face condition, but a significant effect of similarity within the ignore-faces condition (ATT_SIM>ATT_DISS: $F=.10, p=.756$; IGN_SIM $<$ IGN_DISS: $\mathrm{F}=8.67 \mathrm{p}=.013)$. The same $2 \times 2$ ANOVA was performed on the back-projections of the ICs onto the scalp (original space). This analysis, in line with the previous one, revealed an interaction effect $(F(1,11)=8.46, p=.014)$. This interaction reflected, once again, no similarity effect within the attend-to-face condition but a significant difference between the ignore-similarfaces and ignore-dissimilar faces conditions (ATT_SIM>ATT_DISS: $\mathrm{F}=.17, \mathrm{p}=.688 ;$ IGN_SIM $<$. IGN_DISS: $\mathrm{F}=7.59, \mathrm{p}=.019)$.

The IC scalp maps were characterized by a posterior-central distribution. Several studies suggested, based on source modeling, that the N250 is generated in FFA (Schweinberger et al., 2002, 2004, 2007). In addition, our fMRI study showed an interaction effect between attention and similarity bilaterally within FFA. Therefore, similarly to the seeding procedure used for the N170, we modeled the scalp maps of the N250-cluster with two symmetrical dipoles located bilaterally in the middle/anterior part of fusiform gyrus (Fig. 5.b). These dipole models located within FFA accounted on average for $93.22 \%$ of the total variance $(90.17 \%-97.47 \%)$.

The N2b-cluster consisted of 15 components from 11 subjects. The ICs in this cluster were characterized by a large negativity around $270 \mathrm{~ms}$. A $2 \times 2$ ANOVA on the ICs mean amplitudes revealed a main effect of attention and no main effect of similarity or interaction (Fig. 6.a). Attention: $(\mathrm{F}(1,10)=45.092, \mathrm{p}=.000$, mean amplitude $\mathrm{ATT}=-1.649, \mathrm{SE}=.327, \mathrm{IGN}=-.545, \mathrm{SE}=.226)$. Similarity: $(\mathrm{F}(1$, $10)=.001, \mathrm{p}=.980$, mean amplitude $\mathrm{SIM}=-1.096, \mathrm{SE}=.297$, $\mathrm{DISS}=-1.099, \mathrm{SE}=.250)$. Interaction: $(\mathrm{F}(1,10)=.312, \mathrm{p}=.589)$. We found the same pattern of results when we back-projected the ICs of the N2b-cluster onto the scalp. In fact, a $2 \times 2$ ANOVA revealed a 
a

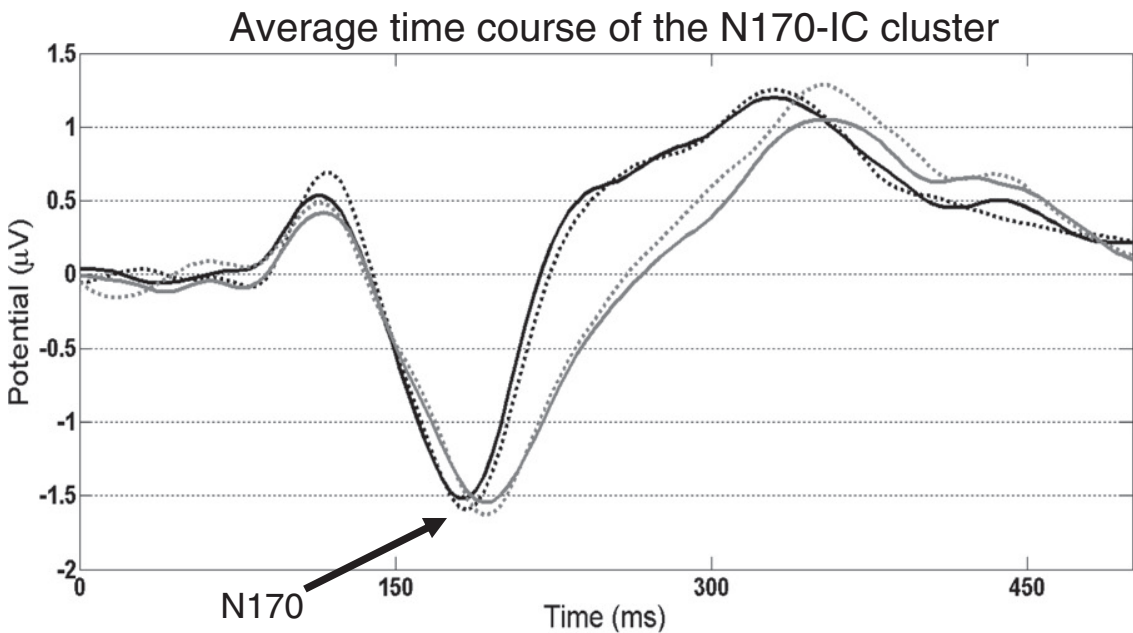

b

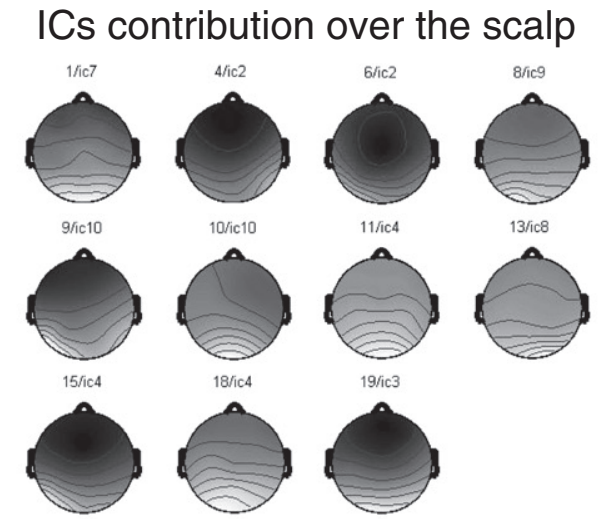

average distribution

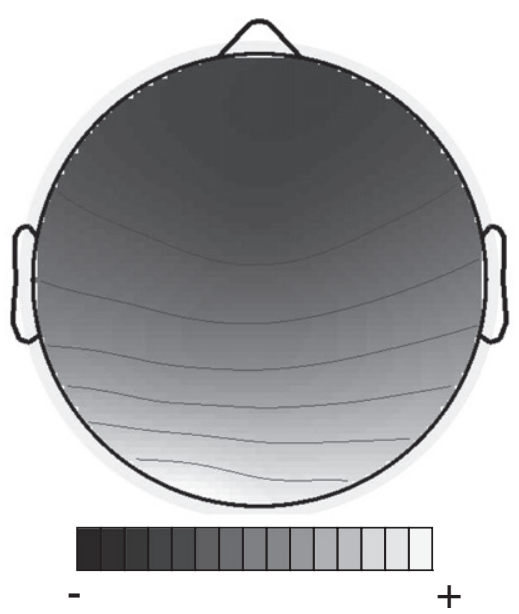

Mean amplitudes

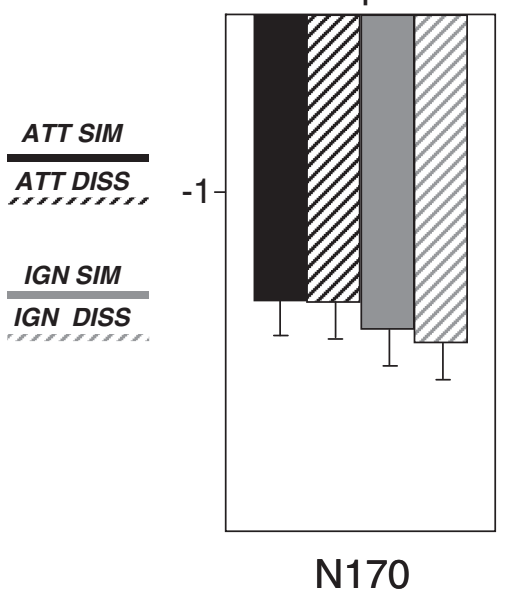

dipole source modeling

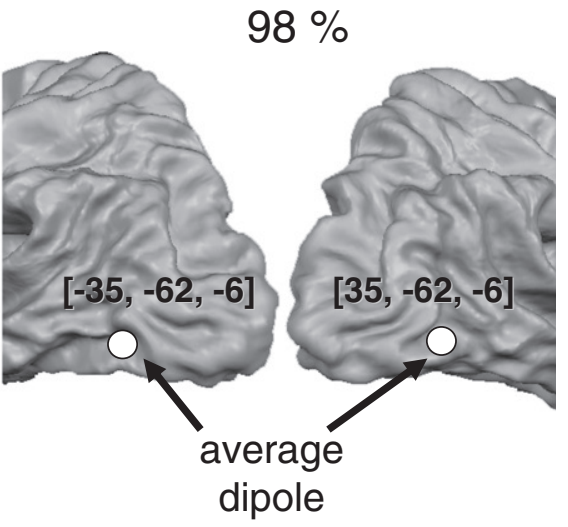

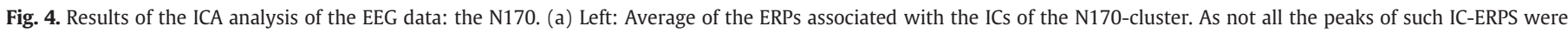

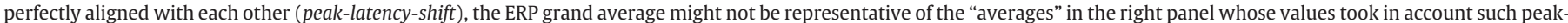

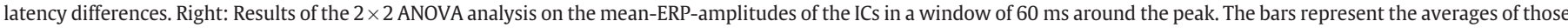

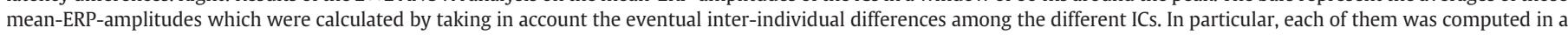

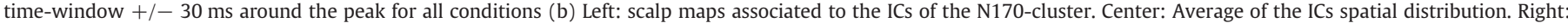
location of the two-dipoles-model used to fit the ICs scalp maps.

main effect of attention $(F(1,10)=29.427, p=.000$, mean amplitude $\mathrm{ATT}=-3.065, \mathrm{SE}=.595, \mathrm{IGN}=-1.324, \mathrm{SE}=.325)$ and no other effects.

The topography associated with the ICs in the N2b-cluster had a fronto-central scalp distribution. In contrast to the N170 and N250 analysis, for the N2b we did not have a clear expectation on the source location of the dipole models. In addition, the fMRI results showed that several frontal areas (bilaterally within the insula and in the right hemisphere within the inferior frontal gyrus, precentral gyrus/sulcus) were involved in the attentional task. Therefore, we did not proceed with seeding dipoles in a specific area. Instead, we computed for each IC an equivalent current dipole (a one or two dipole model) characterized by a projection on the scalp that best-fitted the observed scalp topography of that component. The best fitting dipoles mainly corresponded to a network of regions in the prefrontal cortex comprising the cingulate gyrus, the insula and the inferior frontal gyrus (IFG) (Fig. 6.b). On average these dipoles accounted for $95.04 \%$ of the total variance $(89.21 \%-99.10 \%)$.

In order to test whether the three described clusters were representative respectively for the N170, N250 and N2b ERP component on the scalp, we computed the contribution of the ICback-projections to the grand average ERP in three corresponding time-windows: 140-220 ms (N170), 170-250 ms (N250) and 220$300 \mathrm{~ms}(\mathrm{~N} 2 \mathrm{~b})$. In the $140-220 \mathrm{~ms}$ time-window the ICs in the N170cluster were the components that contributed the most to the grand average for all 4 conditions (ATT_SIM $=38.55 \%$, ATT_DISS $=40.88 \%$, IGN_SIM $=48.34 \%$, IGN_DISS $=55.11 \%$ ). In the second $170-250 \mathrm{~ms}$ time-window we observed that the N250 was the cluster that contributed the most to the signal on the scalp in the ignore-faces conditions (IGN_SIM $=27.59 \%$, IGN_DISS $=28.28 \%$ ). In the same time-window both the N250 and N2b-clusters were relevant in explaining the overall signal in the attend-to-face condition (N250: ATT_SIM $=31.15 \%$, ATT_DISS $=33.37 \%$; N2b: ATT_SIM $=34.35 \%$, ATT_DISS $=37.39 \%$ ). In the third $220-300 \mathrm{~ms}$ time-window the N2b-cluster was the one that contributed the most but only in the attend-to-face condition (ATT_SIM=23.57\%, ATT_DISS = 27.36\%).

\section{Discussion}

In the present study we investigated the temporal properties of face selection in the context of BC, using EEG and ICA. The BC model states that the neural representations of simultaneously presented items compete with each other. Attention biases the neural competition in favor of the object relevant for further cognitive 
a

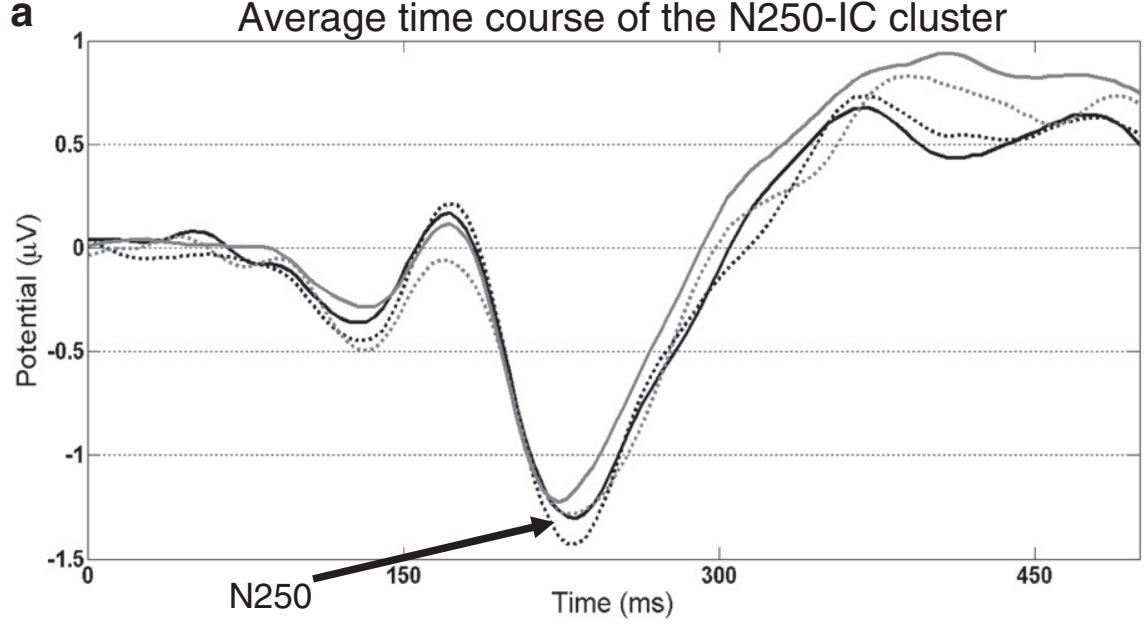

b ICs contribution over the scalp<smiles>c1ccc(C23CC4CC(CC(C4)C2)C3)cc1</smiles>
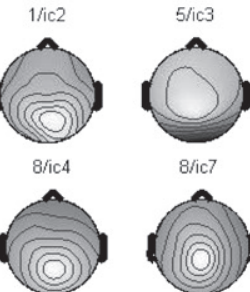

10/ic2<smiles>c1ccc2c(c1)C1c3ccccc3C2c2ccccc21</smiles>

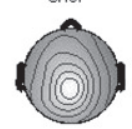

$12 /$ ics
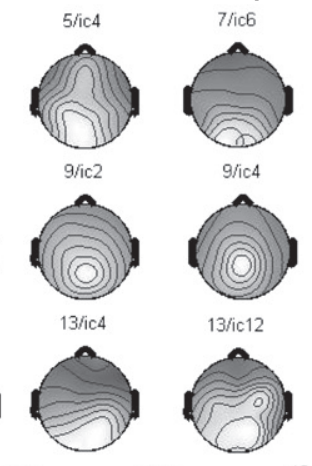

$\infty$

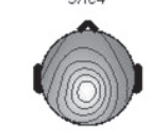

$13 / \mathrm{ic} 12$
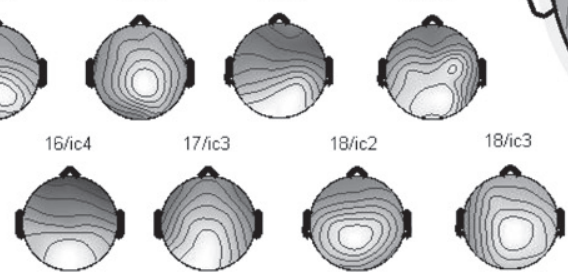

average distribution

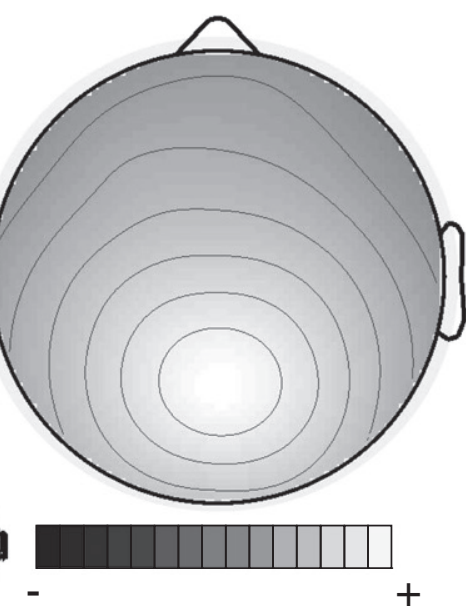

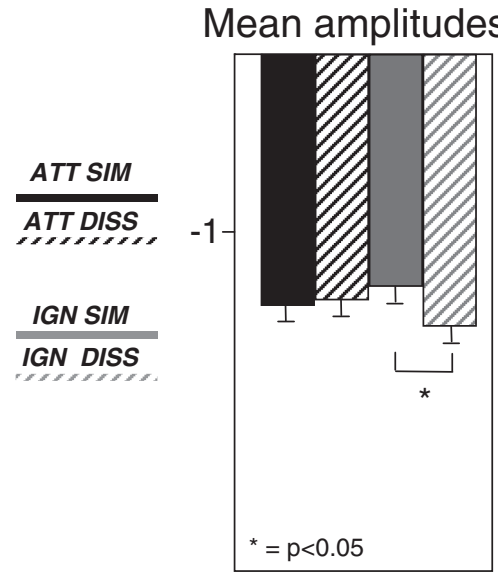

N250

dipole source modeling
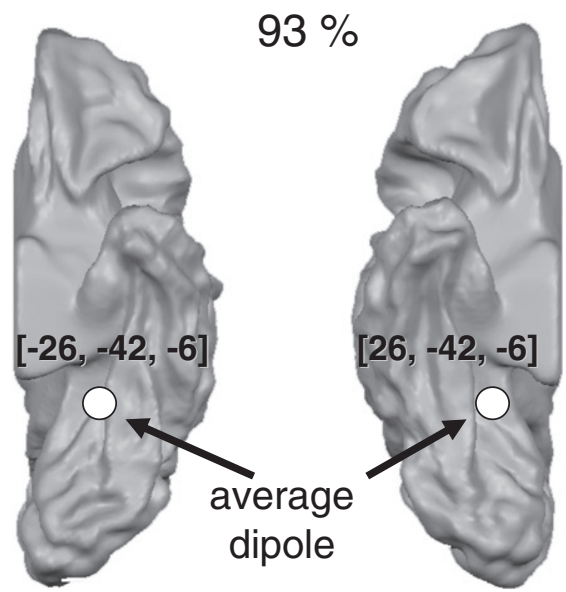

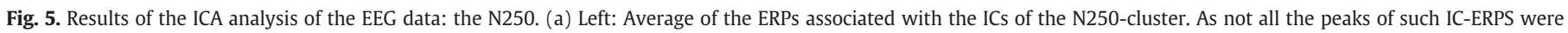

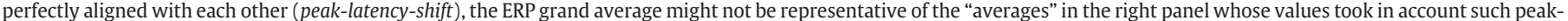

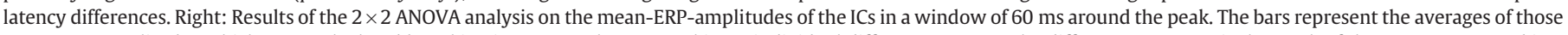

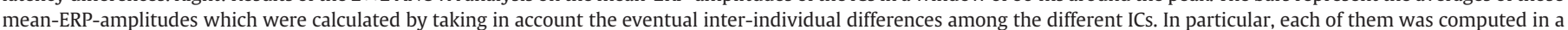

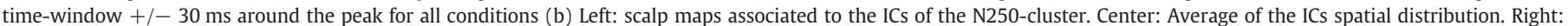
location of the two-dipoles-model used to fit the ICs scalp maps.

processes and behavior. In a preceding fMRI study we tested the BC model by using the same face stimuli, procedure and design as described here. We observed both in OFA and FFA a BC-like activation pattern (IGN_SIM $<$ IGN_DISS - competition; ATT_SIM = ATT_DISS bias). In addition, frontal areas, such as insula, inferior frontal gyrus and precentral gyrus/sulcus showed a main effect of attention and no similarity effect (ATT $>$ IGN), suggesting that these areas triggered the bias (selection) downstream towards OFA and FFA (Gentile and Jansma, 2010). However, the signal we observed in the fMRI experiment was a "summary" of neural events occurring during $500 \mathrm{~ms}$ (trial duration), and could not be used to study temporal dynamics. In the present study we used the high temporal resolution of EEG and focused on ERP components related to face processing and selection. We tested which of these ERP components were sensitive to neural interactions between competitive items (faces) and to the attentional signal that eventually biased such interactions towards the relevant face. The ERP analysis was also used to investigate whether the origin of the attentional modulation that biased competition in OFA and FFA was caused by top-down signals from frontal areas as suggested by our fMRI results.

In this experiment subjects had to carry out a complex task. Several neural mechanisms like face-related processes (i.e., encoding of facial features, the holistic configuration of a face and face recognition), attention (attentional shift and bias) and response execution were involved. This means that several neural sources were at work in overlapping time-courses. As a consequence, several ERP components related to these functions temporally and spatially overlapped on the scalp. In order to investigate the access of the visual information of both face as well as the selection of the relevant one within each source, we needed to disentangle these processes into independent events. This was accomplished by analyzing the EEG data using ICA. The efficacy of this tool has been shown in several EEG experiments both in the temporal (Debener et al., 2005a, 2005b; Makeig et al., 1999a, 1999b) and spectral (Makeig et al., 2002, 2004; Onton et al., 2005; Riecke et al., 2009) domains. We used ICA to search for ICs that represented the ERPs related to the processes involved in the two tasks (ignore-faces/attendto-face tasks) for the two types of stimuli (similar/dissimilar faces).

The ICs extracted from all subjects were divided into clusters according to their temporal and spatial characteristics. In line with the cognitive processes related to the subjects' task we found ICs-clusters associated to face processing and spatial attention ERP component namely the N170, N250 and the N2b. In a nutshell, the pattern of result at the $\mathrm{N} 170$ (no effects) suggested that no competition or bias effect takes place at an early phase of face processing. The analysis of 
a

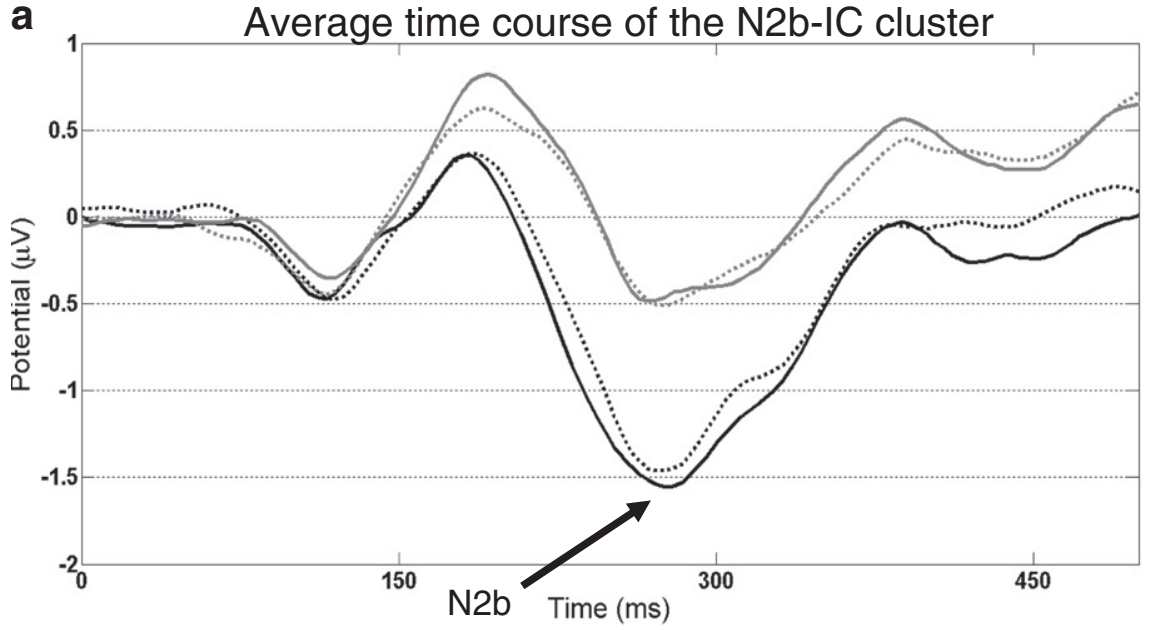

b ICs contribution over the scalp
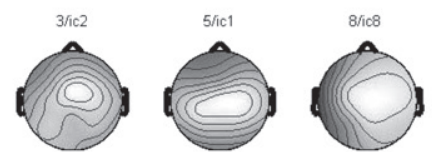

$10 / 1 \mathrm{c} 8$
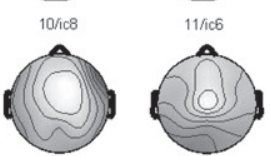

13 ic5

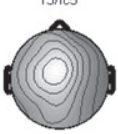

16 /ic1
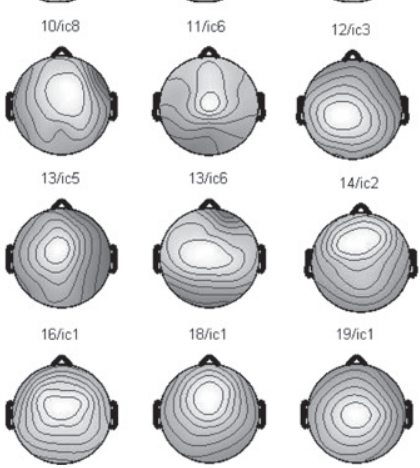

14/ic2

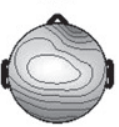

18/ici
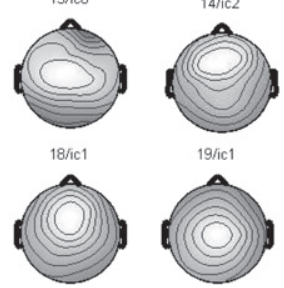

average distribution

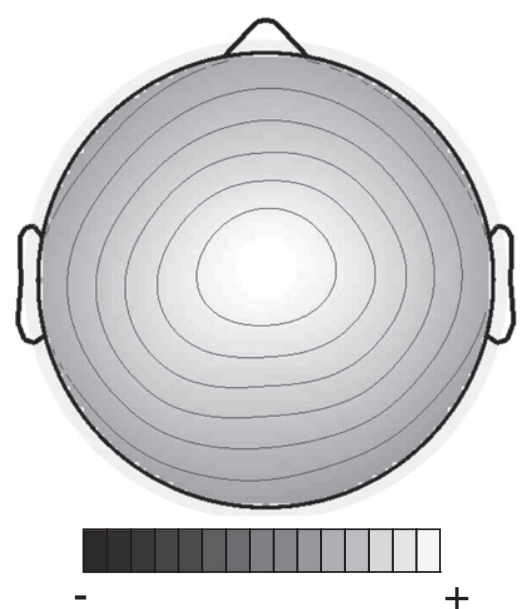

Mean amplitudes

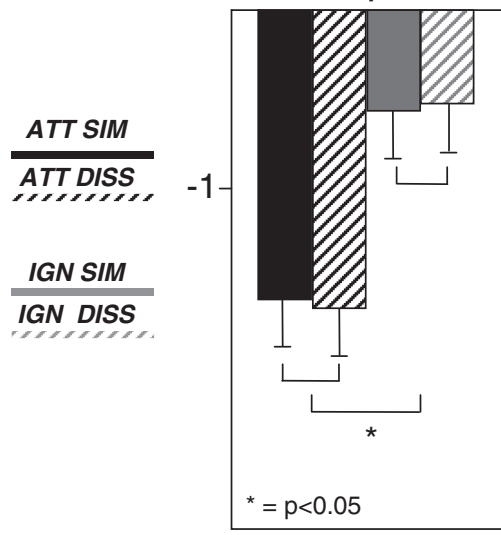

$\mathrm{N} 2 \mathrm{~b}$

\section{dipole source modeling}

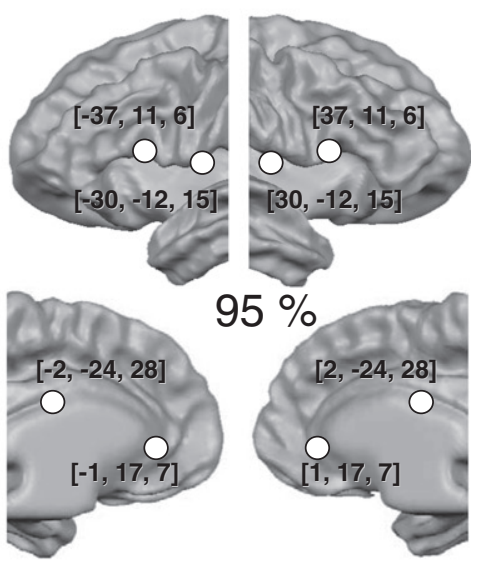

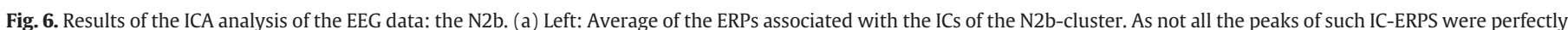

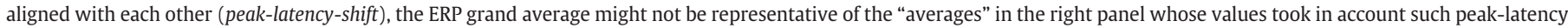

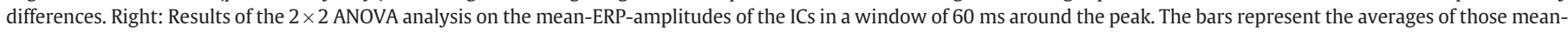

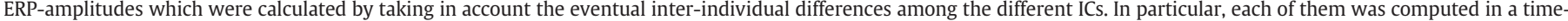

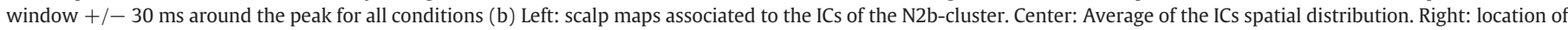
the two-dipoles-model used to fit the ICs scalp maps.

the N250 indicated that faces compete for representation in the ignore-faces condition in a later time-window. In the same timewindow, we found that attention biased neural competition towards the attended face. However, unlike the pattern of the fMRI signal we observed in OFA and FFA, we did not observe a main effect of attention in the N250 time-window. The lack of task effect at the level of the N250 and at earlier stages of processing suggested that the task effect in the fMRI data could only arise from later top-down processing. As expected we found a main effect of attention in the N2b about $50 \mathrm{~ms}$ later than the N250. This temporal delay between the N250 and the $\mathrm{N} 2 \mathrm{~b}$ together with the assumption of maximal independence of ICs indicated that bias and top-down control is independent from each other, and that the bias precedes top-down task-related attentional modulation. It also implied that the significant difference between attend-to-face and ignored-faces condition within OFA and FFA was an effect of temporal integration of the fMRI signal related to several cognitive processes over time.

\section{Neural competition in the N250 time-window}

The occurrence of neural interactions between faces' representations was tested by presenting at the same time and in two different hemifields two similar and dissimilar faces while participants performed an unrelated task in the center of the screen. We investigated with such a task whether two simultaneously presented faces were encoded to a certain extent and compete for neural representation.

The earliest effect of the similarity manipulation within the ignorefaces condition (IGN_SIM $<$ IGN_DISS) was found in correspondence of ICs with a large negativity around $230 \mathrm{~ms}$ and a posterior-central distribution (N250-cluster). The relevance of this result was confirmed by the back-projection of those ICs onto the scalp. This analysis showed the same similarity modulation (IGN_SIM $<$ IGN_DISS) we found at the level of the N250-cluster. The N250-cluster was also the one contributing the most (together with the N2b-cluster) to the grand average ERP measured on the scalp in the time-window 170$250 \mathrm{~ms}$ for all four conditions. This result validated the "goodness" of this cluster as representative of the N250 ERP component on the scalp.

The occipito-temporal N250 has been shown to be face-selective (Nasr and Esteky, 2009; Schweinberger et al., 2004). More specifically, it has been demonstrated that the N250 is sensitive to face familiarity, face repetition (Pfutze et al., 2002; Schweinberger et al., 2004; Tanaka et al., 2006) and it is thought to be related to face identification. In addition, several studies showing that FFA is sensitive to faces presented across both hemifields (Grill-Spector and Malach, 2004; 
Halgren et al., 1999; Kovacs et al., 2008; Large et al., 2008; Reinholz and Pollmann, 2007). Therefore the significant difference between similar and dissimilar pairs of faces within the ignore-faces condition suggested that both faces in the display were simultaneously encoded.

The directionality of this similarity modulation (IGN_SIM $<$ IGN_DISS) was interpreted in line with the neural representation of faces in the context of neural competition. In particular, two recent fMRI studies showed that similar faces are more likely to be encoded by largely overlapping population of neurons. In contrast, dissimilar faces are processed by distinct subpopulation of neurons (Jiang et al., 2006; Loffler et al., 2005). Therefore, when two faces are presented at the same time, the $\mathrm{BC}$ model would predict that they would compete more for representation due to larger inhibition among the neurons in the cohort. This would lead to lower overall activity for the processing of similar compared to dissimilar faces. As expected, the signal amplitude of N250-ICs was lower for similar than dissimilar faces reflecting the occurrence of competitive interactions between the two faces' representations.

It is very unlikely that the significant difference between the ignore-dissimilar-faces vs. ignore-similar-faces condition is related to neural adaptation over time and its difference between the similar and dissimilar conditions. In fact, neural adaptation has normally been tested by using sequences of similar or identical items presented in isolation. In addition none of the models proposed as neural causes of such a mechanism (fatigue, sharpening and facilitation) have been related to the effects normally observed when several items are simultaneously presented (as it is the case of this study). In the present experiment we avoided any adaptation effect due to repetition of similar faces by manipulating the similarity level between faces only at the level of a single trial (within a pair) and not across trials. Neural adaptation was kept constant for both conditions across trials as the pairs of faces presented in a block were different to each other both in the similar and dissimilar condition.

\section{Attentional bias in the N250 time-window}

We investigated the bias component of $\mathrm{BC}$ by including in the design an attentional task where the subject had to covertly attend to the face on the left and performed a match-to-face task. This attendto-face task was needed to test whether attending to one of the faces biased the neural competition (see above) towards that face.

We found that the similarity modulation we observed in the ignore-faces condition disappeared (ATT_SIM = ATT_DISS) at the level of the N250 once the subject shifted the attention to one of the two faces. And this effect held both in the ICs space and on the scalp (ICs back-projected). In line with BC, this lack of similarity modulation within the attend-to-face condition suggested that neural processing was biased towards the perception of the target face only. In fact the N250 might reflect the effect of selecting the relevant face at the target position (Eimer and Kiss, 2010; Theeuwes, 2010).

The bias effect of attention in a competitive system was explained by Reynolds and Desimone (1999) by using the "shrinking receptive field" metaphor. They suggest that the effective spatial resolution of the visual system is enhanced by focusing the attention to the target. This mechanism might be necessary to process only the face in a pair, making it context-independent. This "shrinking" of the receptive field or context independence can be seen as an efficient selection mechanism for relevance in complex scenes - or as tested here - in multiple faces displays.

Although previous studies tested the BC model by using a similar attention task, it is worthwhile to point out that the attentional bias was not the only mechanism to play a role during this task. Spatial attention was also involved. We rejected the alternative option of superimposing the two faces and ask the subject to perform the task on one of them. With such a design we could encounter different level of visibility between the two conditions (similar faces less than dissimilar faces) which would make one condition (dissimilar) easier to perform than the other (similar). Most importantly, superimposed facial stimuli would not occur in real world stimulation and selection, which would make a transfer of experimental data to natural processing rather senseless.

The use of ICA partially overcame the problem of the simultaneous occurrence of the bias and spatial attention by searching for distinct clusters of ICs that might reflect the two attentional components. We excluded the occurrence of a spatial attention mechanism taking place at early stage of visual processing. In fact, the lack of a N1 or P1-ICscluster lateralized on the right (contralateral to the site of attention) suggested that the interaction at the 250 time-window was not influenced by any preceding attentional effect. In addition, Henson and Mouchlianitis (2007) recently found that face-selective areas processed two items placed in opposite hemifields also when one of them was selectively attended. This result is not surprising if we consider the large body of evidence showing the effect of ignored items on attended items at even higher level of processing like at the semantic (Di Pace et al., 1991; Eddy et al., 2006; Tipper and Driver, 1988; Yee, 1991) and phonological level (Bles and Jansma, 2008). Therefore, also for the attend-to-face condition we can assume that the ignored face (the one on the right) was encoded to some extent in face related areas.

In the homologue fMRI study, we reported the same BC-like interactions (IGN_SIM $<$ IGN_DISS; ATT_SIM = ATT_DISS) we found for the N250. This effect was significant both in OFA and FFA (Gentile and Jansma, 2010). In this case, we suggested that the BC mechanism takes place in the two face-selective areas. However, the dipole source analysis suggested that FFA was the only plausible source location for the ICs in the N250-cluster (93.22\% averaged explained variance). This result indicates that FFA plays a central role in selection in the N250time-window, while the OFA activation pattern might derive from a feedback effect from higher order areas like FFA itself (Rossion et al., 2003a).

Despite the similarity of the interaction effect we observed in the EEG and fMRI experiment, the two measurements differed with respect to the main effect of attention we observed in OFA and FFA (fMRI) but not in the N250 (EEG). One of the possible sources of this attentional effect in OFA and FFA could be the bias signal needed to solve the neural competition between the two faces (in the N250 time window-see above)

In this case, the divergence between the fMRI and EEG results is not surprising. In fact, according to the bias model of selection the attentional bias is originated in a fronto-parietal network. Therefore, we would rather expect a main effect of attention at an early latency in fronto-parietal regions. There are at least two explanations for such a lack of attentional effect. First of all, it is important to point out that the criteria used to cluster together ICs with the same topography and ERP morphology were very strict. This was done in order to make the clustering procedure as objective as possible. Such a conservative procedure in combination with the diversity of regions responsible for triggering the bias signal could be the reason why we did not find the "bias" IC-cluster. In fact, it is very likely that the "bias" ICs from different subjects had the same ERP morphology but different topography. In this case they would end up in different clusters, each of them containing a too limited amount of ICs to perform any statistical analysis. In addition to this problem, we should also consider that according to several electrophysiological studies (Gregoriou et al., 2009; Moore and Armstrong, 2003; Moore and Fallah, 2004; Thompson et al., 2005) the amount of frontal neurons sufficient to affect perceptual processing in visual area via attentional mechanism can be very small $(<300)$ Therefore as the EEG reflects the dipole activity of hundreds of neurons that are oriented along the same directions, this technique could just not be sensitive enough to measure the "bias" signal as stated by the bias model of selection. 
In summary, the combination of ICA and ERP analysis revealed that selecting a single face in a pair occurred in a BC-fashion at a relatively late stage of face processing, around $250 \mathrm{~ms}$ post-stimulus onset.

\section{Covert/spatial attentional mechanism in the N2b time-window}

Spatial attention could be another potential mechanism responsible for the significant enhancement of the fMRI signal in OFA and FFA for the attend-to-face compared to the ignore-faces task. The ICA analysis revealed a cluster of ICs that likely reflected such an attentional mechanism. We defined it as the N2b-cluster based on its spatial and temporal characteristics (200-300 ms interval after stimulus onset, distributed frontally and over central electrode sites). The optimal dipole fits related to the N2b activity were located within those fronto-central regions that showed a main effect of attention in the fMRI experiment namely within the insula and the inferior frontal gyrus. In addition, for some ICs the dipoles fitted within the cingulate gyrus which is in line with several source analyses reporting medial brain areas and in particular the anterior cingulate as possible generator of the N2b (Lange et al., 1998).

The N2b-cluster ICs showed a main effect of attention reflecting a significantly larger signal for the attend-to-face than for the ignorefaces condition. The strength of this effect and its relevance over a large time-span was confirmed by the large amount of variance explained by the ICs of the N2b-cluster back-projected on the scalp. In particular, the N2b-cluster was the one contributing the most to the signal on the scalp in two relevant time-windows, i.e. in the 170$250 \mathrm{~ms}$ and in the 220-300 ms time-windows for the attend-to-face condition.

The N2b ERP component is thought to reflect covert orienting attention and the further processing of the selection of the relevant item (Boksem et al., 2005; Lange et al., 1998; Luck and Hillyard, 1994; Okita et al., 1985; Sams et al., 1983; Wijers et al., 1989a, 1989b). Lange et al. (1998) also demonstrated that the N2b was elicited for a large set of attended objects confirming its specificity to attentional selection. The N2b was also elicited in match-to-sample tasks where participants were presented with items not matching the actual target (Sams et al., 1983).

In the attend-to-face condition of the present experiment similar mechanisms were involved. In particular, covert attention took place in order to shift the focus of attention from the center of the screen to the left. Subsequently, selective attention was needed to perform the match-to-sample task. Therefore, the N2b-cluster ICs likely reflected these attentional components. In addition, in the present analysis all the matched target trials were not included. Hence, the N2b-ICs could also be the marker of a template mismatch effect. The effect of attention at the level of the N2b cannot be explained by a general facilitation effect in the execution of the ignore-faces compared to the attend-to-face task (no behavioral differences). It also cannot be related to a higher amount of eye movement in the attend-to-face task (see Gentile and Jansma, 2010, where we reported the statistical analysis on the eye movements of the present experiment - no significant differences across conditions, $4 \%$ eye-movement trials in total).

These results confirmed the idea that one of the sources of the attentional main effect in OFA and FFA (fMRI study) originated from a distributed network in the prefrontal cortex, active in the N2b timewindow. In line with the assumptions of the ICA algorithm, these findings also suggested that the attend-to-face task gave rise to two different attentional effects: one at the level of the N250 and the other associated with the N2b. In particular, as the former was related to a face-related ERP component and it was localized at occipito-temporal sites is likely to correspond to the attentional bias component. In contrast, for the frontal N2b we found a clear task effect suggesting the occurrence of the spatial attentional mechanism at this latency. Therefore, the attentional process identified by the N2b cannot be the direct cause of the bias effect, as the bias was observed at an earlier latency (at the N250 level). Most likely frontal sources are needed to properly perform the match-to-face task by amplifying the encoding of the "already biased" face. However, due to the nature of the attendto-face task we cannot completely exclude the possibility that the two attentional components might actually influence each other.

\section{The lack of modulation for the N170}

The IC cluster analysis also identified a N170-cluster whose components were characterized by a negative deflection around $180 \mathrm{~ms}$. In order to test whether this cluster was representative of the N170 ERP on the scalp we computed the variance explained by the back-projected ICs to the negative signal on the scalp. The N170cluster turned out to be the one that contributed the most to the signal on the scalp in the $140-220 \mathrm{~ms}$ time-window. The topography associated with the ICs showed an occipito-central distribution. These maps were modeled with two equivalent dipoles located in the lateral bank of LOC, recently identified with the OFA. The high amount of variance explained ( $96.23 \%$ on average) by such a model confirmed the results from those source localization studies that anatomically associated the N170 to the OFA (Botzel et al., 1995; Deffke et al., 2007; Pizzagalli et al., 2002; Rossion et al., 2003b; Schweinberger et al., 2002; Shibata et al., 2002).

Although the N170 and the OFA (as measured in fMRI) showed a reasonable anatomical fit, the two measurements based on either hemodynamic response or post-synaptic potential differed in several aspects at the functional level. The statistical analysis on the mean amplitude around the N170 peak did not show any significant modulation. Such a lack of attentional and similarity effects suggests that the system has not yet processed the two faces in context. One explanation might be that the two faces are not yet encoded at all. Alternatively, at this early stage of face processing faces might still be processed in terms of their basic components. Therefore, the absence of any similarity modulation within the ignore-faces condition would imply that faces do not compete at the featural level. A third option is that the two faces were both encoded but at a N170 time-window the system could still be blind to their identities mostly if we consider that the subjects was performing an unrelated task and faces were not actively attended. In more general terms, we can conclude that the selection of a face in the context of another face does not occur in the N170-timewindow and most importantly it does not take place in line with the BC model.

In a recent study, Furey et al. (2006) showed a very similar divergence while measuring with magnetoencephalography (MEG) and fMRI the effect of attention on face processing. They observed that the hemodynamic response in the fusiform and inferior occipital cortex was strongly modulated when attention was focused on faces compared to houses. The same pattern was not found at the level of the early face-selective response (M170). The only modulation of the MEG signal was found in a later stage of processing identified as "category-related" component. In line with these results the interaction of factors attention and similarity at the level of the N250 suggests that attention only affect a later stage of face processing.

In conclusion, the present study demonstrated that ICA can be a very powerful tool to investigate the brain dynamics and to (re) interpret the fMRI results. ICA was successfully used here to study the effects of facial similarity in face selection. In fact, the ICA found, in a data-driven fashion, those ERP components known to be the most relevant for face processing (N170 and N250) and attention (N2b). Most importantly the anatomical and functional correspondence between the fMRI and ERP/ICs data allowed us to track the temporal profile of the selection mechanism of a face in the context of another face. We showed that when two faces were simultaneously presented 
and ignored they compete for representation in a relatively late stage of face processing (N250) in FFA. In addition, when the target face was attended to, similar and dissimilar conditions elicited the same EEG signal. This indicates that in the N250 time-window an attentional bias solved the neural competition between faces within FFA. This interpretation of results supported the $\mathrm{BC}$ model in the context of face selection. Finally, the combination of the EEG and fMRI results suggested that the bias effect that solves neural competition in FFA is not driven by any bottom-up signal from OFA into FFA, but is FFAspecific and might represent the initial stage of selection.

\section{Acknowledgments}

The authors wish to thank Lisa Jonkman, Peter de Weerd and Mart Bles for helpful discussions. This project was supported by Maastricht University (HRM initiative Mobilizing Minds: "Females into higher positions") to B.M. Jansma.

\section{References}

Beck, D.M., Kastner, S., 2005. Stimulus context modulates competition in human extrastriate cortex. Nat. Neurosci. 8, 1110-1116.

Beck, D.M., Kastner, S., 2007. Stimulus similarity modulates competitive interactions in human visual cortex. J. Vis. 7 (19), 11-12.

Bentin, S., Allison, T., Puce, A., Perez, E., McCarthy, G., 1996. Electrophysiological studies of face perception in humans. J. Cogn. Neurosci. 551-565.

Bles, M., Jansma, B.M., 2008. Phonological processing of ignored distractor pictures, an fMRI investigation. BMC Neurosci. 9, 20.

Bles, M., Schwarzbach, J., De Weerd, P., Goebel, R., Jansma, B.M., 2006. Receptive field size-dependent attention effects in simultaneously presented stimulus displays. Neuroimage 30, 506-511.

Boksem, M.A., Meijman, T.F., Lorist, M.M., 2005. Effects of mental fatigue on attention: an ERP study. Brain Res. Cogn. Brain Res. 25, 107-116.

Botzel, K., Schulze, S., Stodieck, S.R., 1995. Scalp topography and analysis of intracranial sources of face-evoked potentials. Exp. Brain Res. 104, 135-143.

Brefczynski, J.A., DeYoe, E.A., 1999. A physiological correlate of the 'spotlight' of visual attention. Nat. Neurosci. 2, 370-374.

Broadbent, D., 1958. Perception and Communication Pergamon. Elmsford, New York.

Carrasco, M., Ling, S., Read, S., 2004. Attention alters appearance. Nat. Neurosci. 7 , 308-313.

Chelazzi, L., Duncan, J., Miller, E.K., Desimone, R., 1998. Responses of neurons in inferior temporal cortex during memory-guided visual search. J. Neurophysiol. 80, 2918-2940.

Chelazzi, L., Miller, E.K., Duncan, J., Desimone, R., 2001. Responses of neurons in macaque area V4 during memory-guided visual search. Cereb. Cortex 11, 761-772.

Debener, S., Makeig, S., Delorme, A., Engel, A.K., 2005a. What is novel in the novelty oddball paradigm? Functional significance of the novelty P3 event-related potential as revealed by independent component analysis. Brain Res. Cogn. Brain Res. 22, 309-321.

Debener, S., Ullsperger, M., Siegel, M., Fiehler, K., von Cramon, D.Y., Engel, A.K., 2005b. Trial-by-trial coupling of concurrent electroencephalogram and functional magnetic resonance imaging identifies the dynamics of performance monitoring. J. Neurosci. 25, 11730-11737.

Deffke, I., Sander, T., Heidenreich, J., Sommer, W., Curio, G., Trahms, L., Lueschow, A 2007. MEG/EEG sources of the 170 -ms response to faces are co-localized in the fusiform gyrus. Neuroimage 35, 1495-1501.

Desimone, R., 1998. Visual attention mediated by biased competition in extrastriate visual cortex. Philos. Trans. R. Soc. Lond. B Biol. Sci. 353, 1245-1255.

Desimone, R., Duncan, J., 1995. Neural mechanisms of selective visual attention. Annu. Rev. Neurosci. 18, 193-222.

Di Pace, E., Longoni, A.M., Zoccolotti, P., 1991. Semantic processing of unattended parafoveal words. Acta Psychol. (Amst) 77, 21-34.

Eddy, M., Schmid, A., Holcomb, P.J., 2006. Masked repetition priming and event-related brain potentials: a new approach for tracking the time-course of object perception. Psychophysiology 43, 564-568.

Eimer, M., Kiss, M., 2010. The top-down control of visual selection and how it is linked to the N2pc component. Acta Psychol. (Amst) 135, 100-102; (discussion 133-109).

Fujita, I., Tanaka, K., Ito, M., Cheng, K., 1992. Columns for visual features of objects in monkey inferotemporal cortex. Nature 360, 343-346.

Furey, M.L., Tanskanen, T., Beauchamp, M.S., Avikainen, S., Uutela, K., Hari, R., Haxby, J.V., 2006. Dissociation of face-selective cortical responses by attention. Proc. Natl. Acad. Sci. U.S.A. 103, 1065-1070

Gauthier, I., Tarr, M.J., Moylan, J., Skudlarski, P., Gore, J.C., Anderson, A.W., 2000. The fusiform "face area" is part of a network that processes faces at the individual level. J. Cogn. Neurosci. 12, 495-504.

Gentile, F., Jansma, B.M., 2010. Neural competition through visual similarity in face selection. Brain Res. 1351, 172-184.

Gregoriou, G.G., Gotts, S.J., Zhou, H., Desimone, R., 2009. High-frequency, long-range coupling between prefrontal and visual cortex during attention. Science 324 1207-1210.
Grill-Spector, K., Malach, R., 2004. The human visual cortex. Annu. Rev. Neurosci. 27, 649-677.

Halgren, E., Dale, A.M., Sereno, M.I., Tootell, R.B., Marinkovic, K., Rosen, B.R., 1999. Location of human face-selective cortex with respect to retinotopic areas. Hum. Brain Mapp. 7, 29-37

Hawkins, H.L., Hillyard, S.A., Luck, S.J., Mouloua, M., Downing, C.J., Woodward, D.P., 1990. Visual attention modulates signal detectability. J. Exp. Psychol. Hum. Percept. Perform. 16, 802-811.

Henson, R.N., Mouchlianitis, E., 2007. Effect of spatial attention on stimulus-specific haemodynamic repetition effects. Neuroimage 35, 1317-1329.

Henson, R.N., Mattout, J., Singh, K.D., Barnes, G.R., Hillebrand, A., Friston, K., 2007. Population-level inferences for distributed MEG source localization under multiple constraints: application to face-evoked fields. Neuroimage 38, 422-438.

Herrmann, M.J., Ehlis, A.C., Muehlberger, A., Fallgatter, A.J., 2005. Source localization of early stages of face processing. Brain Topogr. 18, 77-85.

Hillyard, S.A., Munte, T.F., 1984. Selective attention to color and location: an analysis with event-related brain potentials. Percept. Psychophys. 36, 185-198.

Jacques, C., Rossion, B., 2004. Concurrent processing reveals competition between visual representations of faces. Neuroreport 15, 2417-2421.

Jacques, C., Rossion, B., 2006. The time course of visual competition to the presentation of centrally fixated faces. J. Vis. 6, 154-162.

Jacques, C., Rossion, B., 2007. Electrophysiological evidence for temporal dissociation between spatial attention and sensory competition during human face processing. Cereb. Cortex 17, 1055-1065.

Jacques, C., Rossion, B., 2009. The initial representation of individual faces in the right occipito-temporal cortex is holistic: electrophysiological evidence from the composite face illusion. J. Vis. 9 (8), 1-16.

Jeffreys, D.A., 1989. A face-responsive potential recorded from the human scalp. Exp. Brain Res. 78, 193-202.

Jiang, X., Rosen, E., Zeffiro, T., Vanmeter, J., Blanz, V., Riesenhuber, M., 2006. Evaluation of a shape-based model of human face discrimination using FMRI and behavioral techniques. Neuron 50, 159-172.

Kanwisher, N., McDermott, J., Chun, M.M., 1997. The fusiform face area: a module in human extrastriate cortex specialized for face perception. J. Neurosci. 17, 4302-4311.

Kastner, S., Ungerleider, L.G., 2000. Mechanisms of visual attention in the human cortex. Annu. Rev. Neurosci. 23, 315-341.

Kastner, S., Ungerleider, L.G., 2001. The neural basis of biased competition in human visual cortex. Neuropsychologia 39, 1263-1276.

Kastner, S., De Weerd, P., Desimone, R., Ungerleider, L.G., 1998. Mechanisms of directed attention in the human extrastriate cortex as revealed by functional MRI. Science 282, 108-111.

Kastner, S., Pinsk, M.A., De Weerd, P., Desimone, R., Ungerleider, L.G., 1999. Increased activity in human visual cortex during directed attention in the absence of visual stimulation. Neuron 22, 751-761.

Kastner, S., De Weerd, P., Pinsk, M.A., Elizondo, M.I., Desimone, R., Ungerleider, L.G., 2001. Modulation of sensory suppression: implications for receptive field sizes in the human visual cortex. J. Neurophysiol. 86, 1398-1411.

Kayser, S., 1985. Heads. Abbeville Press, New York.

Klem, G.H., Luders, H.O., Jasper, H.H., Elger, C. 1999. The ten-twenty electrode system of the International Federation. The International Federation of Clinical Neurophysiology. Electroencephalogr. Clin. Neurophysiol. Suppl. 52, 3-6.

Kovacs, G., Cziraki, C., Vidnyanszky, Z., Schweinberger, S.R., Greenlee, M.W., 2008. Position-specific and position-invariant face aftereffects reflect the adaptation of different cortical areas. Neuroimage 43, 156-164.

Kreiman, G., Hung, C.P., Kraskov, A., Quiroga, R.Q., Poggio, T., DiCarlo, J.J., 2006. Object selectivity of local field potentials and spikes in the macaque inferior temporal cortex. Neuron 49, 433-445.

Lange, J.J., Wijers, A.A., Mulder, L.J., Mulder, G., 1998. Color selection and location selection in ERPs: differences, similarities and 'neural specificity'. Biol. Psychol. 48, 153-182.

Large, M.E., Culham, J., Kuchinad, A., Aldcroft, A., Vilis, T., 2008. fMRI reveals greater within- than between-hemifield integration in the human lateral occipital cortex. Eur. J. Neurosci. 27, 3299-3309.

Loffler, G., Yourganov, G., Wilkinson, F., Wilson, H.R., 2005. fMRI evidence for the neural representation of faces. Nat. Neurosci. 8, 1386-1390.

Luck, S.J., Hillyard, S.A., 1994. Electrophysiological correlates of feature analysis during visual search. Psychophysiology 31, 291-308.

Luck, S.J., Hillyard, S.A., Mouloua, M., Woldorff, M.G., Clark, V.P., Hawkins, H.L., 1994. Effects of spatial cuing on luminance detectability: psychophysical and electrophysiological evidence for early selection. J. Exp. Psychol. Hum. Percept. Perform. 20, 887-904.

Luck, S.J., Chelazzi, L., Hillyard, S.A., Desimone, R., 1997. Neural mechanisms of spatial selective attention in areas V1, V2, and V4 of macaque visual cortex. J. Neurophysiol. 77, 24-42.

Makeig, S., Westerfield, M., Jung, T.P., Covington, J., Townsend, J., Sejnowski, T.J., Courchesne, E., 1999a. Functionally independent components of the late positive event-related potential during visual spatial attention. J. Neurosci. 19, 2665-2680.

Makeig, S., Westerfield, M., Townsend, J., Jung, T.P., Courchesne, E., Sejnowski, T.J., 1999b. Functionally independent components of early event-related potentials in a visual spatial attention task. Philos. Trans. R. Soc. Lond. B Biol. Sci. 354, 1135-1144.

Makeig, S., Westerfield, M., Jung, T.P., Enghoff, S., Townsend, J., Courchesne, E., Sejnowski, T.J., 2002. Dynamic brain sources of visual evoked responses. Science 295, 690-694.

Makeig, S., Debener, S., Onton, J., Delorme, A., 2004. Mining event-related brain dynamics. Trends Cogn. Sci. 8, 204-210. 
Miller, E.K., Gochin, P.M., Gross, C.G., 1993. Suppression of visual responses of neurons in inferior temporal cortex of the awake macaque by addition of a second stimulus. Brain Res. 616, 25-29.

Mnatsakanian, E.V., Tarkka, I.M., 2004. Familiar-face recognition and comparison: source analysis of scalp-recorded event-related potentials. Clin. Neurophysiol. 115, 880-886.

Moore, T., Armstrong, K.M., 2003. Selective gating of visual signals by microstimulation of frontal cortex. Nature 421, 370-373.

Moore, T., Fallah, M., 2004. Microstimulation of the frontal eye field and its effects on covert spatial attention. J. Neurophysiol. 91, 152-162.

Moran, J., Desimone, R., 1985. Selective attention gates visual processing in the extrastriate cortex. Science 229, 782-784.

Nasr, S., Esteky, H., 2009. A study of N250 event-related brain potential during face and non-face detection tasks. J. Vis. 9 (5), 1-14.

Okita, T., Wijers, A.A., Mulder, G., Mulder, L.J., 1985. Memory search and visual spatial attention: an event-related brain potential analysis. Acta Psychol. (Amst) 60, 263-292.

Onton, J., Makeig, S., 2006. Information-based modeling of event-related brain dynamics. Prog. Brain Res. 159, 99-120.

Onton, J., Delorme, A., Makeig, S., 2005. Frontal midline EEG dynamics during working memory. Neuroimage 27, 341-356.

Pessoa, L., Kastner, S., Ungerleider, L.G., 2003. Neuroimaging studies of attention: from modulation of sensory processing to top-down control. J. Neurosci. 23, 3990-3998.

Pfutze, E.M., Sommer, W., Schweinberger, S.R., 2002. Age-related slowing in face and name recognition: evidence from event-related brain potentials. Psychol. Aging 17, $140-160$.

Pizzagalli, D.A., Lehmann, D., Hendrick, A.M., Regard, M., Pascual-Marqui, R.D., Davidson, R.J., 2002. Affective judgments of faces modulate early activity (approximately $160 \mathrm{~ms}$ ) within the fusiform gyri. Neuroimage 16, 663-677.

Posner, M.I., Snyder, C.R., Davidson, B.J., 1980. Attention and the detection of signals. J. Exp. Psychol. 109, 160-174.

Recanzone, G.H., 2000. Spatial processing in the auditory cortex of the macaque monkey. Proc. Natl. Acad. Sci. U.S.A. 97, 11829-11835.

Reddy, L., Kanwisher, N.G., VanRullen, R., 2009. Attention and biased competition in multi-voxel object representations. Proc. Natl. Acad. Sci. U.S.A. 106, 21447-21452.

Reinholz, J., Pollmann, S., 2007. Neural basis of redundancy effects in visual object categorization. Neurosci. Lett. 412, 123-128.

Reynolds, J.H., Desimone, R., 1999. The role of neural mechanisms of attention in solving the binding problem. Neuron 24 (19-29), 111-125.

Reynolds, J.H., Chelazzi, L., Desimone, R., 1999. Competitive mechanisms subserve attention in macaque areas V2 and V4. J. Neurosci. 19, 1736-1753.

Reynolds, J.H., Pasternak, T., Desimone, R., 2000. Attention increases sensitivity of V4 neurons. Neuron 26, 703-714.

Riecke, L., Esposito, F., Bonte, M., Formisano, E., 2009. Hearing illusory sounds in noise: the timing of sensory-perceptual transformations in auditory cortex. Neuron 64 550-561.

Rossion, B., Jacques, C., 2008. Does physical interstimulus variance account for early electrophysiological face sensitive responses in the human brain? Ten lessons on the N170. Neuroimage 39, 1959-1979.

Rossion, B., Caldara, R., Seghier, M., Schuller, A.M., Lazeyras, F., Mayer, E., 2003a. A network of occipito-temporal face-sensitive areas besides the right middle fusiform gyrus is necessary for normal face processing. Brain 126, 2381-2395.

Rossion, B., Joyce, C.A., Cottrell, G.W., Tarr, M.J., 2003b. Early lateralization and orientation tuning for face, word, and object processing in the visual cortex. Neuroimage 20, 1609-1624.

Sams, M., Alho, K., Naatanen, R., 1983. Sequential effects on the ERP in discriminating two stimuli. Biol. Psychol. 17, 41-58.
Sato, T., Uchida, G., Tanifuji, M., 2009. Cortical columnar organization is reconsidered in inferior temporal cortex. Cereb. Cortex 19 (8), 1870-1888.

Schweinberger, S.R., Pickering, E.C., Jentzsch, I., Burton, A.M., Kaufmann, J.M., 2002. Event-related brain potential evidence for a response of inferior temporal cortex to familiar face repetitions. Brain Res. Cogn. Brain Res. 14, 398-409.

Schweinberger, S.R., Huddy, V., Burton, A.M., 2004. N250r: a face-selective brain response to stimulus repetitions. Neuroreport 15, 1501-1505.

Schweinberger, S.R., Kaufmann, J.M., Moratti, S., Keil, A., Burton, A.M., 2007. Brain responses to repetitions of human and animal faces, inverted faces, and objects: an MEG study. Brain Res. 1184, 226-233.

Shibata, T., Nishijo, H., Tamura, R., Miyamoto, K., Eifuku, S., Endo, S., Ono, T., 2002. Generators of visual evoked potentials for faces and eyes in the human brain as determined by dipole localization. Brain Topogr. 15, 51-63.

Steeves, J.K., Culham, J.C., Duchaine, B.C., Pratesi, C.C., Valyear, K.F., Schindler, I., Humphrey, G.K., Milner, A.D., Goodale, M.A., 2006. The fusiform face area is not sufficient for face recognition: evidence from a patient with dense prosopagnosia and no occipital face area. Neuropsychologia 44, 594-609.

Steyvers, M., Busey, T., 2000. Predicting Similarity Ratings to Faces using Physical Descriptions. In: Computational, geometric, and process perspectives on facial cognition: Contexts and challenges. Lawrence Erlbaum Associates.

Tamura, H., Kaneko, H., Fujita, I., 2005. Quantitative analysis of functional clustering of neurons in the macaque inferior temporal cortex. Neurosci. Res. 52, 311-322.

Tanaka, K., 2003. Columns for complex visual object features in the inferotemporal cortex: clustering of cells with similar but slightly different stimulus selectivities. Cereb. Cortex 13, 90-99.

Tanaka, J.W., Curran, T., Porterfield, A.L., Collins, D., 2006. Activation of preexisting and acquired face representations: the N250 event-related potential as an index of face familiarity. J. Cogn. Neurosci. 18, 1488-1497.

Theeuwes, J., 2010. Top-down and bottom-up control of visual selection. Acta Psychol. (Amst) 135, 77-99.

Thompson, K.G., Biscoe, K.L., Sato, T.R., 2005. Neuronal basis of covert spatial attention in the frontal eye field. J. Neurosci. 25, 9479-9487.

Tipper, S.P., Driver, J., 1988. Negative priming between pictures and words in a selective attention task: evidence for semantic processing of ignored stimuli. Mem. Cognit. $16,64-70$.

Treisman, A.M., 1969. Strategies and models of selective attention. Psychol. Rev. 76, 282-299.

Treue, S., Martinez Trujillo, J.C., 1999. Feature-based attention influences motion processing gain in macaque visual cortex. Nature 399, 575-579.

Treue, S., Maunsell, J.H., 1996. Attentional modulation of visual motion processing in cortical areas MT and MST. Nature 382, 539-541.

Wang, G., Tanifuji, M., Tanaka, K., 1998. Functional architecture in monkey inferotemporal cortex revealed by in vivo optical imaging. Neurosci. Res. 32, 33-46.

Wijers, A.A., Mulder, G., Okita, T., Mulder, L.J., Scheffers, M.K., 1989a. Attention to color: an analysis of selection, controlled search, and motor activation, using eventrelated potentials. Psychophysiology 26, 89-109.

Wijers, A.A., Otten, L.J., Feenstra, S., Mulder, G., Mulder, L.J., 1989b. Brain potentials during selective attention, memory search, and mental rotation. Psychophysiology $26,452-467$.

Williams, E.J., 1949. Experimental designs balanced for the estimation of residual effects of treatments. Aust. J. Sci. Res. 2, 149-168.

Wojciulik, E., Kanwisher, N., Driver, J., 1998. Covert visual attention modulates face-specific activity in the human fusiform gyrus: fMRI study. J. Neurophysiol. 79, 1574-1578.

Yee, P.L., 1991. Semantic inhibition of ignored words during a figure classification task. Q. J. Exp. Psychol. A 43, 127-153.

Young, M.P., Yamane, S., 1992. Sparse population coding of faces in the inferotemporal cortex. Science 256, 1327-1331. 